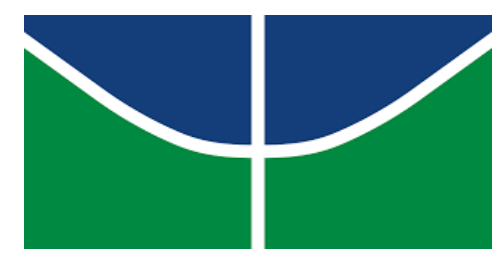

UNIVERSIDADE DE BRASÍLIA

FACULDADE DE TECNOLOGIA

DEPARTAMENTO DE ENGENHARIA FLORESTAL

ALEXANDRE EURICO TEZA DE SOUZA

AVALIAÇÃO DE SEMENTES DE Myracrodruon urundeuva Fr. All. SUBMETIDAS A TRÊS MÉTODOS DE ANÁLISE DO TEOR DE UMIDADE 
Brasília - DF

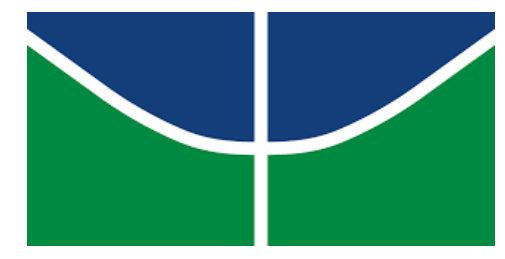

UNIVERSIDADE DE BRASÍLIA

FACULDADE DE TECNOLOGIA

DEPARTAMENTO DE ENGENHARIA FLORESTAL

\section{AVALIAÇÃO DE SEMENTES DE Myracrodruon urundeuva Fr. All. SUBMETIDAS A TRÊS MÉTODOS DE ANÁLISE DO TEOR DE UMIDADE}

Aluno: Alexandre Eurico Teza de Souza

Orientadora: Profa. Rosana de Carvalho Cristo Martins

Co-orientador: Prof. Ildeu Soares Martins

Projeto de trabalho de conclusão de curso apresentado ao Departamento de Engenharia Florestal da Universidade de Brasília, como parte das exigências para obtenção do título de Engenheiro Florestal.

Brasília, 18 de agosto de 2017. 


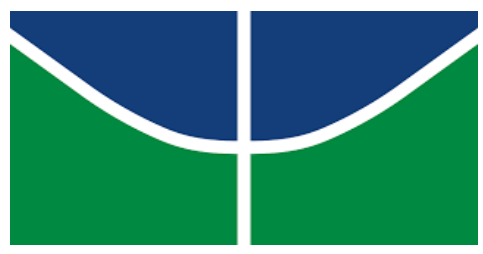

UNIVERSIDADE DE BRASÍLIA

FACULDADE DE TECNOLOGIA

DEPARTAMENTO DE ENGENHARIA FLORESTAL

\section{AVALIAÇÃO DE SEMENTES DE Myracrodruon urundeuva Fr. All. SUBMETIDAS A TRÊS MÉTODOS DE ANÁLISE DO TEOR DE UMIDADE}

Estudante: Alexandre Eurico Teza de Souza

Matrícula: 11/0072006

Orientador: Prof ${ }^{\mathrm{a}}$. Dra. Rosana de Carvalho Cristo Martins

Menção:

Aprovado por:

Prof ${ }^{a}$. Dra. Rosana de Carvalho Cristo Martins

Universidade de Brasília - UnB

Departamento de Engenharia Florestal

Orientadora

Prof. Dr. Ildeu Soares Martins

Universidade de Brasília - UnB

Departamento de Engenharia Florestal

Coorientador

Dra. Juliana Martins de Mesquita Matos

Universidade de Brasília - UnB

Faculdade de Agronomia e Medicina Veterinária

Membro da banca

Brasília /2017. 
A todos aqueles que de alguma forma estiveram e estão próximos de mim, fazendo esta vida valer cada vez mais a pena. 


\section{AGRADECIMENTOS}

Agradeço aos meus ancestrais.

Agradeço aos meus pais.

Agradeço ao meu irmão.

Agradeço a minha irmã.

Agradeço a Dodora.

Agradeço ao Thiago Caneiro dos Santos.

Agradeço aos meus sogros.

Agradeço aos funcionários da Universidade.

Agradeço ao Restaurante Universitário.

Agradeço ao Manel.

Agradeço ao Cubano.

Agradeço ao Derek.

Agradeço a todos os meus colegas.

Agradeço a todos os meus professores.

Agradeço a todos os meus amigos.

Agradeço a todos os meus simpatizantes.

Agradeço a Nação.

Agradeço a professora Rosana pela disponibilidade de tempo para me ajudar, pela sua paciência com as minhas falhas e meus atrasos.

Agradeço ao professor Ildeu pelos conselhos e ensinamentos durante as aulas de genética e pela disponibilidade em me ajudar. 
"Tchau, brigaaaado".

Juliano Reys 


\section{RESUMO}

O mercado brasileiro necessita de técnicas para desenvolvimento da produção de mudas de espécies nativas provenientes de sementes. O método desenvolvido, ainda, mais efetivo é a secagem dos propágulos para o armazenamento, sendo uma ferramenta para a conservação das espécies que estão ameaçadas pela alta exploração. A espécie Myracrodruon urundeuva é um exemplo do uso desenfreado devido sua madeira de alta densidade e presença de tanino, além das suas propriedades farmacológicas. O trabalho teve como objetivo avaliar o métodos de secagem das sementes de $M$. urundeuva em estufa, em aparelho micro-ondas e aparelho medidor de umidade analisando a viabilidade fisiológica das sementes de por meio do teste de germinação. $\mathrm{O}$ experimento foi realizado utilizando 30 matrizes com quatro repetições, a quantidade de semente variou de acordo com o teste, no de germinação empregou-se 40 semente e nos de secagem 135 sementes. O delineamento foi inteiramente casualizado (DIC), usando a análise de variância (ANOVA) ao nível 5\% de significância e o teste de Tukey. A espécie apresentou boa taxa de germinação ocorrendo nos primeiros dias de experimento. Os métodos de secagem diferiram estatisticamente entre si, não podendo eleger o melhor para a espécie, pois é necessario considerar os objetivos finais do processo a ser escolhido.

Palavras-chave: Secagem, semente nativa do cerrado, micro-ondas. 


\begin{abstract}
The Brazilian market needs techniques to develop seedlings production of native species from seeds. The most effective method is the drying of the propagules for storage, being a tool for the conservation of the species that are threatened by high exploitation. The species Myracrodruon urundeuva is an example of the unrestrained use due to its wood of high density and presence of tannin, besides its pharmacological properties. The objective of this work was to evaluate the drying methods of the $\mathrm{M}$. urundeuva seeds in a greenhouse, in a microwave apparatus and a moisture meter, analyzing the physiological viability of the seeds by means of the germination test. The experiment was carried out using 30 matrices with four replicates, the amount of seed varied according to the test, in the germination 40 seed was used and in the drying 135 seeds. The design was completely randomized (DIC), using analysis of variance (ANOVA) at the 5\% level of significance and the Tukey test. The species presented a good germination rate occurring in the first days of the experiment. The drying methods differed statistically from one another, and it was not possible to choose the best for the species, since it is necessary to consider the final objectives of the process to be chosen.
\end{abstract}

Key words: drying, native seed of cerrado, microwave. 


\section{SUMÁRIO}

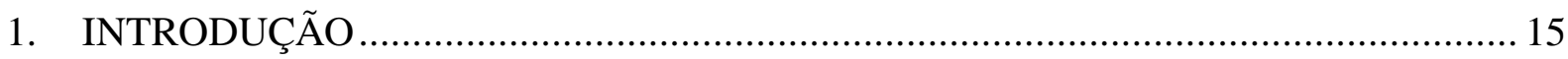

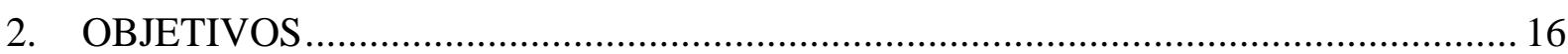

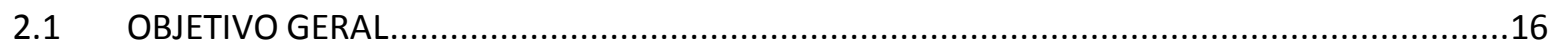

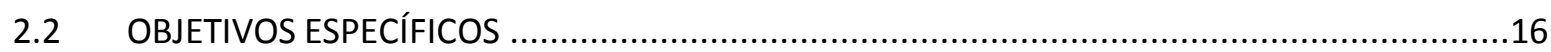

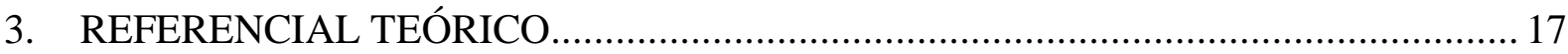

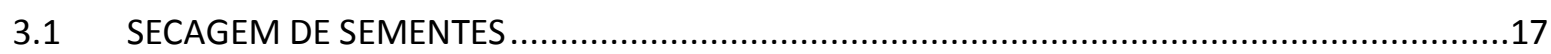

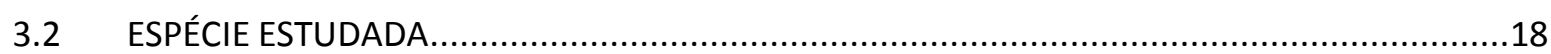

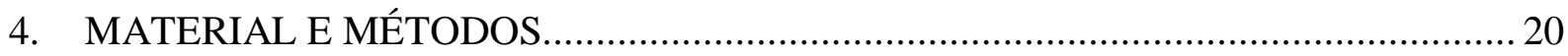

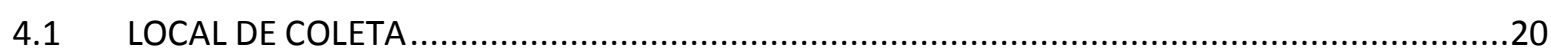

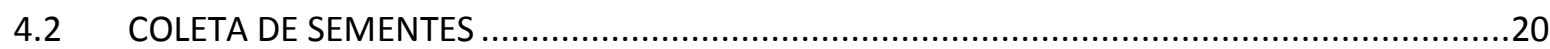

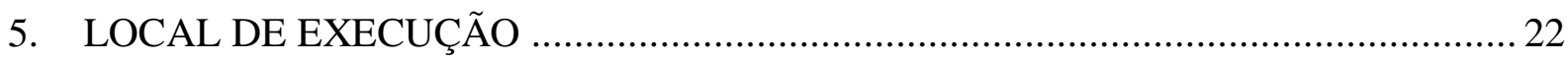

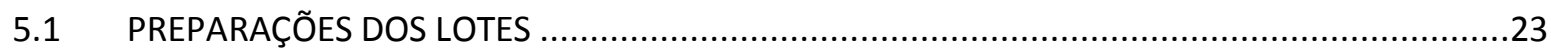

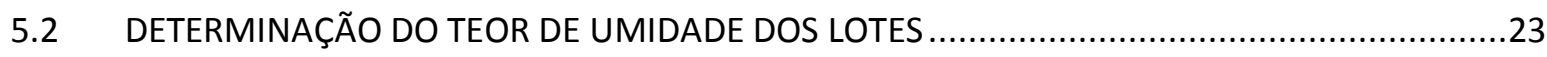

5.2.1 DETERMINAÇÃO DO TEOR DE UMIDADE PELO MÉTODO DA ESTUFA - MÉTODO 1.........23

5.2.2 DETERMINAÇÃO DO TEOR DE UMIDADE PELO MÉTODO DO APARELHO DE MICRO-

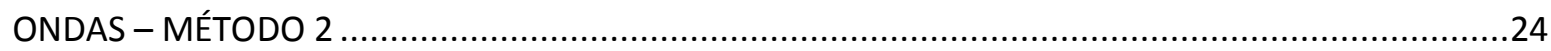

5.2.3 DETERMINAÇÃO DO TEOR DE UMIDADE PELO MÉTODO DO APARELHO MEDIDOR DE

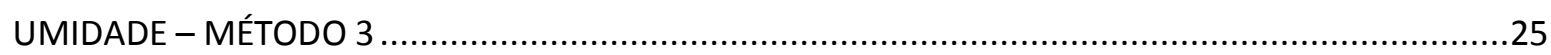

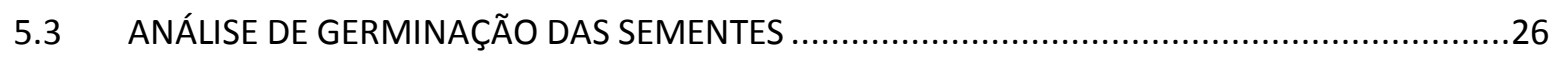

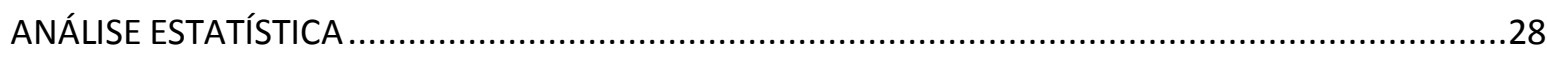

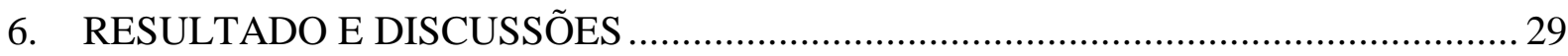

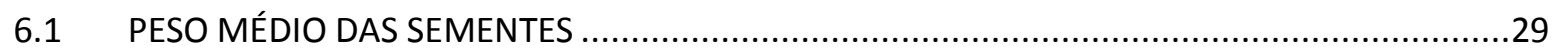

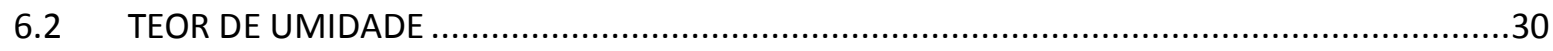

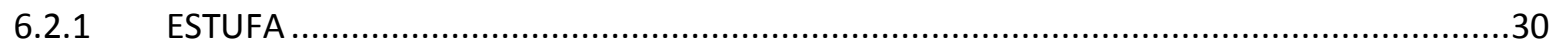

6.2.2 APARELHO MEDIDOR DE UMIDADE …………......................................................

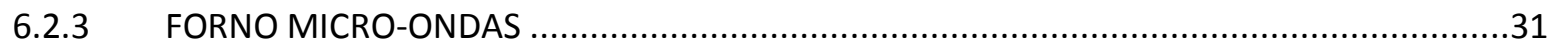

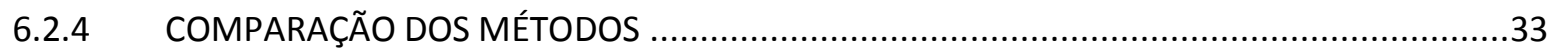

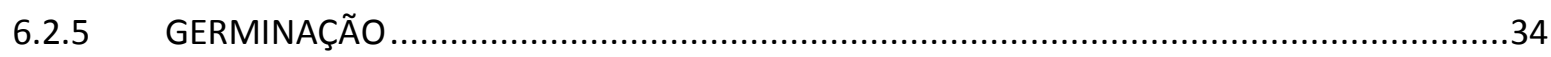

7. CONCLUSÃO

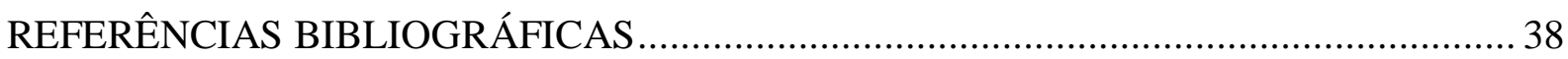




\section{LISTA DE TABELAS}

Tabela 1: Médias do teor de umidade avaliadas nos tratamentos de secagem em estufa (Estufa), secagem em aparelho micro-ondas (Micro) e secagem em aparelho medidor de umidade (Medidor) aplicados em Myracrodruon urundeuva...... 


\section{LISTA DE QUADROS}

Quadro 1: Georreferenciamento das matrizes coletadas.................................................... 21 Quadro 2: Determinação de umidade das sementes de Myracrodruon urundeuva empregandose a metodologia da "Amostra Única” (NERY et al., 2004). 


\section{LISTA DE FIGURAS}

Figura 1: Local de Coleta. Fonte: Souza (2017)............................................................ 20

Figura 2: Coleta de sementes de Myracrodruon urundeuva. Fonte: Souza (2017)................ 21

Figura 3: Distribuição e localização espacial das matrizes de Myracrodruon urundeuva coletadas do presente estudo. Fonte: Google Earth (2017) .................................................. 22

Figura 4: Recipientes metálicos no dessecador. Souza (2017)............................................ 24

Figura 5: Disposição das placas de petri e Becker no prato do aparelho micro-ondas. Fonte:

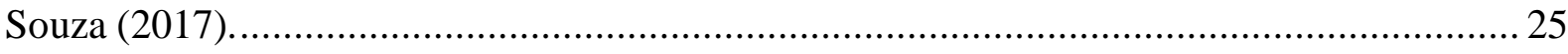

Figura 6: Medidor de umidade com uma repetição. Fonte: Souza (2017)........................... 26

Figura 7: Disposição dos propágulos sobre folhas de papel filtro. Fonte: Souza (2017) ........ 27

Figura 8: Propágulo com radícula igual ou superior a 2,0 $\mathrm{mm}$ sobre papel quadriculado $1 \mathrm{x} 1$

cm. Fonte: Souza (2017). .................................................................................... 27

Figura 9: Peso médio das sementes para cada matriz de Myracrodruon urundeuva. ............ 29

Figura 10: Média das sementes das matrizes de Myracrodruon urundeuva secas em estufa a

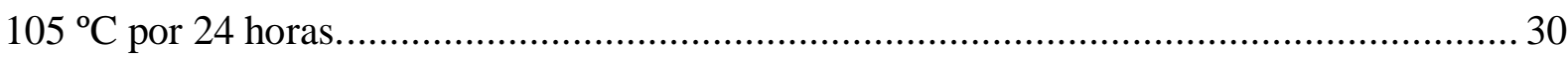

Figura 11: Média das sementes das matrizes de Myracrodruon urundeuva secas no medidor de umidade modelo ID200 na programação automática.

Figura 12: Média das sementes das matrizes de Myracrodruon urundeuva secas no forno

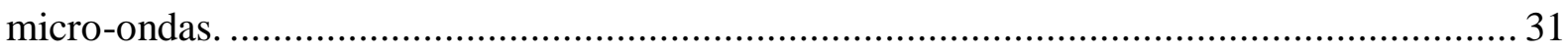

Figura 13: Soma do teor de umidade médio nos tempos 3, 5 e 7 do método 3 $3 . . . \ldots \ldots \ldots . . . . . . . . . .32$

Figura 14: Comparação da soma do teor médio de umidade nos tempos 3, 5 e 7, e nos tempos

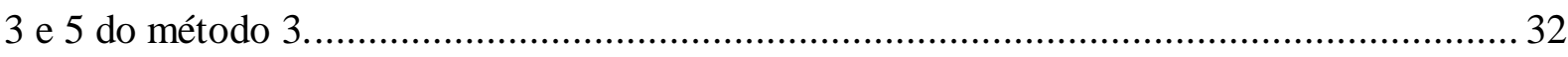

Figura 15:Comparação da retirada de umidade dos métodos 1,2 e 3 . .................................. 33

Figura 16: Germinação média das sementes em percentagem para cada matriz..................... 35

Figura 17: Germinação diária após o estabelecimento do experimento ............................... 36 


\section{Lista de Equações}

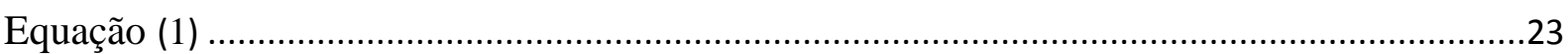




\section{INTRODUÇÃO}

A qualidade das mudas produzidas em larga escala nos viveiros espalhados pelo país possui uma relação direta, entre outros fatores, com a qualidade do material de propagação (HARTMANN; KESTER, 1981). O abastecimento das indústrias de base florestal se dá principalmente pela utilização de técnicas de propagação vegetativa, tendo como ator principal o gênero Eucalyptus. No entanto, uma grande fatia dos produtores, principalmente médios e pequenos, destinam seus viveiros para a produção de mudas de espécies nativas, com o objetivo de alcançar o mercado de recuperação da vegetação de ambientes com interferência antrópica (IBÁ, 2016; STURION; ANTUNES, 2000).

Sabe-se que devido a recente preocupação da sociedade com os problemas ambientais, bem como a falta de capital de pequenos e médios viveiristas (LORZA et al., 2006) não há hoje avanços significativos em relação a técnicas de propagação vegetativa para espécies com menor valor comercial ou de menor demanda. Sendo assim, esses utilizam, de forma majoritária, sementes para o estabelecimento do seu plantel de mudas (CUNHA et al., 2005; STURION; ANTUNES, 2000).

Segundo Hartmann e Kester (1981), a utilização de sementes como método de propagação em larga escala possui pontos positivos e negativos. Pode-se destacar como pontos positivos: a variabilidade genética, custo relativamente baixo, baixa tecnificação e fácil treinamento dos funcionários do viveiro, mas por outro lado, também há pontos negativos, como por exemplo a variabilidade de fenótipos, dificuldade no controle dos cruzamentos dentro da população, desenvolvimento heterogêneo dos indivíduos, tempo das mudas no viveiro e o armazenamento.

O armazenamento de diásporos, segundo Meneghello (2014), configura-se como uma fase de extrema importância para o sucesso de um plantio florestal.

A viabilidade e conservação da semente durante o armazenamento é influenciada diretamente pela umidade encontrada nos propágulos e no ambiente, sendo a capacidade de resiliência ao efeito de dessecação, uma de suas mais importantes propriedades (MEDEIROS; EIRA, 2006).

Tendo em vista a quantidade de espécies florestais presentes no cerrado (MENDONÇA et al., 2008) a importância da secagem das sementes na conservação e a abundância de respostas das mesmas a diferentes níveis de umidade, faz-se necessário 
identificar um método eficiente que possa ser condizente com a realidade dos viveiristas brasileiros, possibilitando a diversificação da produção de espécies.

Entre as inúmeras espécies do Cerrado, a Myracrodruon urundeuva, vulgarmente conhecida como aroeira destaca-se como uma espécie com enorme potencial. Devido a sua multiplicidade de usos a aroeira encontra-se hoje como uma espécie ameaçada de extinção, logo, estudo que viabilizem e difundam a propagação da espécie se fazem necessários (SCALON; SCALON FILHO; MASSETTO, 2012).

\section{OBJETIVOS}

\subsection{OBJETIVO GERAL}

Averiguar a efetividade do método de secagem em forno micro-ondas em comparação aos métodos de estufa convencional $\left(105^{\circ} \mathrm{C} \pm 3^{\circ} \mathrm{C}\right)$ e aparelho medidor de umidade na determinação do teor de umidade de sementes de Myracrodruon urundeuva Fr. All, e analisar a qualidade fisiológica das sementes utilizando o teste de germinação.

\subsection{OBJETIVOS ESPECÍFICOS}

$\checkmark$ Determinar se método de secagem do micro-ondas através da metodologia da “Amostra Única" é adequado para verificação do teor de umidade em sementes de Myracrodruon urundeuva;

$\checkmark$ Determinar se método de secagem do micro-ondas através da metodologia da “Amostra Única” é adequado para verificação do teor de umidade em sementes de Myracrodruon urundeuva;

$\checkmark$ Avaliar a qualidade fisiológica das sementes de Myracrodruon urundeuva através do teste de germinação. 


\section{REFERENCIAL TEÓRICO}

\subsection{SECAGEM DE SEMENTES}

Apesar das várias tentativas de encontrar novas condições de amazenamento de sementes a principal, ainda, é a redução do metabolismo através da remoção da água ou diminuição da temperatura. Os altos níveis de umidade relativa do ar devem ser evitados quando estas se destinam ao armazenamento, pois este fator contribui para a rápida deteorização dos propágulos e facilita o ataque de organismos indesejáveis. $\mathrm{O}$ desenvolvimento de tecnologia para a conservação do material de propagação se faz necessário frente ao número elevado de espécies nativas que ainda se encontram no limbo acadêmico (SOUZA, 2001; KOHOMA et al., 2006).

A secagem é uma das mais importantes etapas da produção de sementes porque quando são colhidas elas apresentam teor de água superior ao mínimo necessário à sua conservação segura, o qual torna a secagem imprescindível. Segundo CARVALHO \& NAKAGAWA (2000), o processo de secagem é composto por duas fases: a primeira caracteriza-se pela perda da água superficial das sementes para o ar circundante e a outra é o processo onde a agua transloca das camadas mais internas para as mais externas, essa transloção dependendo da velocidade pode ocasionar lesões nos tecidos que a compõem. As características que estão diretamente ligadas ao processo de secagem são: temperatura, umidade relativa e vazão do ar, tempo de permanência do produto na câmara de secagem e teores de água inicial e final das sementes (CHRIST et al., 1997)

Pode-se secar a semente naturalmente ou artificialmente. Quando é optado pelo método natural, as sementes são dispostas no ambiente e esse regula a suas perdas e a velocidade com que elas ocorrem, geralmente, esse processo é lento e pode trazer prejuízos a sementes recalcitrantes na qualidade fisiológica. Os processos de secagem artificiais são baseados na circulação de ar em um ambiente isolado hermeticamente forçando a liberação da água contida na semente para o ar desse, por ser um processo mais rápido há uma redução no tempo que os propágulos ficam com altos teores de água, resultando no beneficiamento da sua conservação. (SILVA, 2015).

$\mathrm{O}$ método artificial mais difundido entre os pesquisadores e o que possui maior número de protocolos é o da estufa. Esse processo destaca pela praticidade e pela aplicabilidade em qualquer espécie vegetal. Pela falta de desenvolvimento tecnológico e 
científico os processos alternativos são comumente renegados. $O$ incentivo a melhor utilização de métodos pouco conhecidos poderia diminuir algumas lacunas deixadas pelos métodos oficiais como por exemplo o custo elevado de aplicação (SARMENTO et al., 2015).

Um dos métodos pouco utilizados é a secagem de diásporos em aparelho microondas. Pode-se entende-la como um processo que gera calor no interior do material vegetal, que, consequentemente, acarreta na elevação da temperatura do interior até a superfície do material (BARBOZA et al., 2001).

A grande vantagem da secagem em micro-ondas em relação a da estufa é que a potência e o tempo de secagem podem ser calibrados para os diferentes tipos e quantidades de amostra. O aquecimento por micro- ondas gera economia de energia por não aquecer o equipamento e o ar de secagem que removerá a água do alimento. Toda a energia aplicada será direcionada para o alimento reduzindo os danos à qualidade química, nutricional e sensorial bem como resultados rápidos e precisos na determinação do teor de água em produtos alimentícios (GARCIA et al., 2014).

O aquecimento por microondas é efetuado por radiações sobre as moléculas de água (dipolos) que se aquecem pela oscilação a altas frequiências. Pelas características intrínsecas do método do micro-ondas a remoção da água ocorre em um curto período de tempo, é alegado que existe menos perda de componentes voláteis do que em estufas convencionais ( PEDROSA et al., 2014).

\subsection{ESPÉCIE ESTUDADA}

Devido a sua ampla distribuição geográfica no continente Sul-Americano (Argentina, Bolívia e Paraguai) e também vasta ocorrência no território brasileiro (Alagoas; Bahia; Ceará; Espírito Santo; Goiás; Maranhão; Mato Grosso; Mato Grosso do Sul; Minas Gerais; Paraíba; Pernambuco; Piauí; Rio de Janeiro; Rio Grande do Norte; Sergipe; São Paulo; Tocantins; Distrito Federal) a espécie Myracrodruon urundeuva possui inúmeras denominações regionais, sendo recorrentemente chamada de Aroeira ou Aroeira-Verdadeira (CARVALHO, 2003a).

A palavra "Aroeira", arara + eira, significa local das araras por servir de pouso e alimento para os psitacídeos (MONTEIRO et al., 2012). A percepção popular dos hábitos desses animais em relação à espécie se comprova cientificamente (NUNES; SANTOS JUNIOR, 2011;). Não somente o seu fruto, uma drupa globosa de coloração preta com 
aproximadamente $5 \mathrm{~mm}$ de diâmetro e cálice persistente, mas também suas folhas compostas, imparipinadas de inserção alterna, com 5 a 7 pares de folíolos opostos ovalados (), são consumidas pelas aves (OLMOS; SILVA 1997). Entre os meses de agosto a outubro, período da maturação dos frutos, esses se tornam ainda mais importantes na dieta desses animais pela baixa disponibilidade de outras fontes alimentares (VASCONSELOS et al., 2006).

Utilizada desde antes da descoberta da América pelos europeus (BACHELET et al., 2011; SANTOS 2009), a aroeira se faz presente, de Norte a Sul do país, no cotidiano cultural popular por meio de canções, poesias, contos e ditados. $\mathrm{Na}$ medicina alternativa, principalmente no Nordeste (LUCENA et al., 2011), o extrato da entrecasca, dos brotos, raízes e folhas é recomendado para o tratamento de feridas gastrointestinais, inflamações, doenças ginecológicas, dermatológicas, bucais e venéreas (CAVALCANTI, 2013; MATOS, 2007). Graças as suas propriedades terapêuticas, a necessidade de desenvolvimento de novos medicamentos (OMS, 2014), o alto custo das drogas alopáticas e a busca da população por tratamentos menos agressivos ao organismo, vários estudos estão sendo desenvolvidos para averiguar o real potencial farmacológico da espécie (ALVES et al., 2009; BOTELHO et al., 2007; CARLINI et al., 2010; CHAGAS, 2015; GOES et al., 2005).

Apesar de a espécie decídua, heliófila e seletiva xerófita, pertencente à família Anacardiacea (LORENZI, 1992) ser nativa da Mata Atlântica, Caatinga e Cerrado (CARVALHO, 2003b), em 2008 foi adicionada na lista de espécies ameaçadas de extinção devido a sua super exploração (MMA, 2008), esta por sua vez, justificada pela alta densidade da madeira e presença de taninos (LORENZI, 1992).

Sua alta densidade e suas características químicas possibilitam o seu emprego em estruturas de uso externo em contato direto com as intempéries do meio e aplicação em curtumes (BORGES et al., 2016).

Outro fator impactante sobre a necessidade de estudos para a manutenção da M. urundeuva foi descrito por Nunes et al (2008) onde o autor conclui que a aroeira é altamente sensível aos fatores ambientais, logo, há a necessidade de estudar técnicas que consigam isolar ou reduzir a influência destas variáveis para se ter uma melhora na propagação sexuada. 


\section{MATERIAL E MÉTODOS}

\subsection{LOCAL DE COLETA}

Realizou-se a coleta das sementes de Myracroduon urundeuva na propriedade rural "Fazenda Bebedouro", localizada no município de Abadia de Goiás, no Estado de Goiás, durante os dias 2 e 3 de outubro de 2017. Nos dias anteriores à coleta houve pancadas de chuva na região.

Segundo a classificação de Köppen, a região caracteriza-se como Aw, apresentando invernos secos e verões chuvosos com períodos de estiagem conhecidos como veranicos. A temperatura média é de $22,5{ }^{\circ} \mathrm{C}$ e a precipitação média em torno de $1.469 \mathrm{~mm}$ ao ano. Setembro mostra-se como o mês mais quente do ano $\left(24,1^{\circ} \mathrm{C}\right)$ e Junho o mais frio $\left(19,7{ }^{\circ} \mathrm{C}\right)$ (Climate-data.org, 2017).

O relevo pode ser classificado como fortemente ondulado ou montanhoso (Figura 1) tendo como solo predominante o tipo Cambissolo Háplico com presença de cascalho e silte.

As matrizes de Myracrodruon urundeuva encontram-se em fragmentos de cerradão intensamente antropizados.

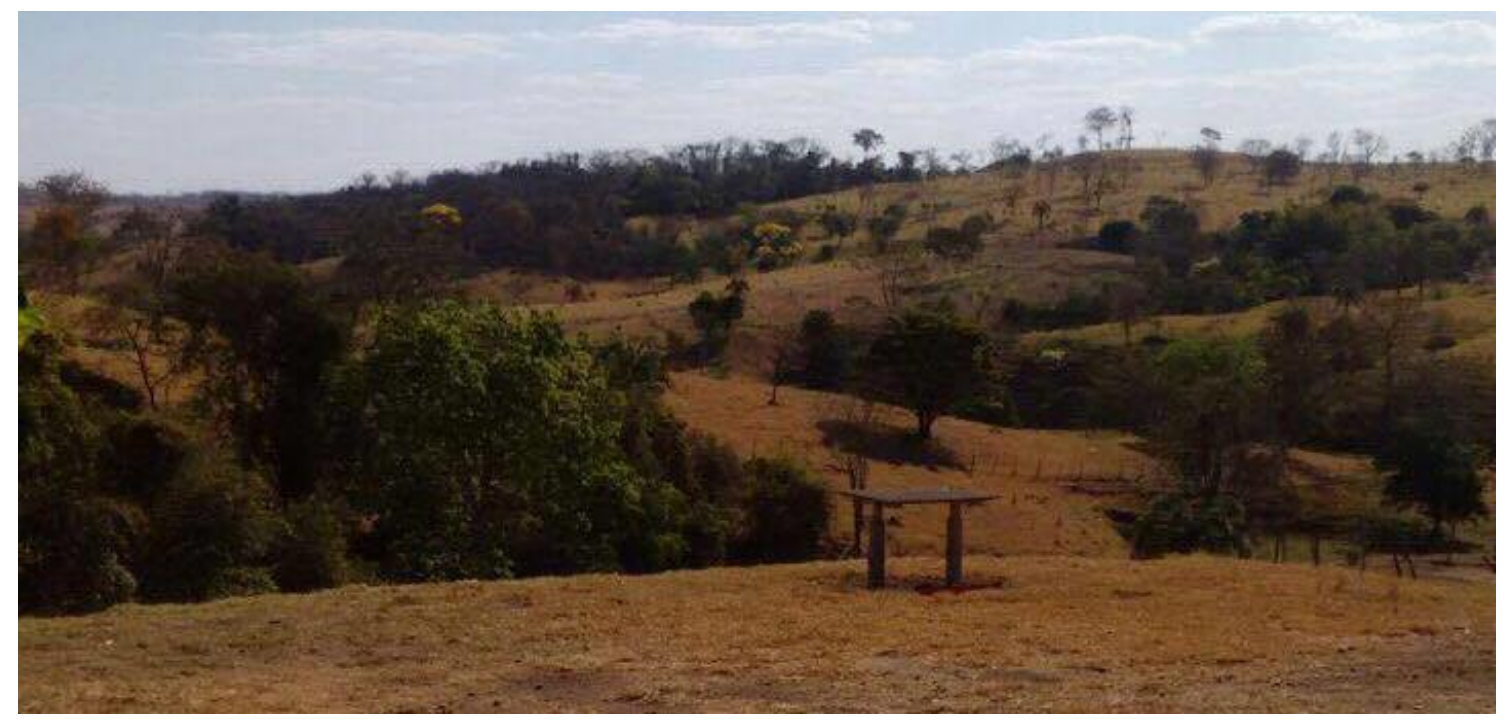

Figura 1: Local de Coleta. Fonte: Souza (2017).

\subsection{COLETA DE SEMENTES}

Neste estudo, para facilitar a compreensão do texto, as drupas de $M$. urundeuva foram referidas simplesmente como "sementes". 
A coleta das sementes deu-se da seguinte forma: Estendeu-se uma lona plástica no solo próximo às matrizes e com auxílio de um podão (Figura 2) os frutos foram coletados de 30 árvores previamente georreferenciadas (Quadro 1).

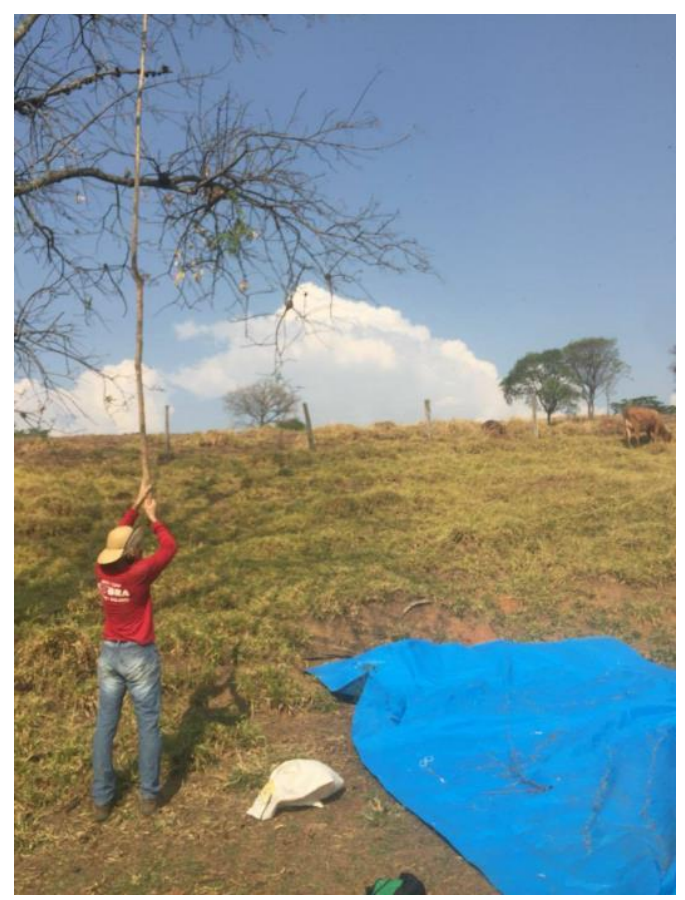

Figura 2: Coleta de sementes de Myracrodruon urundeuva. Fonte: Souza (2017).

Quadro 1: Georreferenciamento das matrizes coletadas.

\begin{tabular}{|c|c|c|c|}
\hline Matrizes & Logitude (S) & Latitude (W) & Altitude (m) \\
\hline 1 & $16^{\circ} 44^{\prime} 47.562^{\prime \prime}$ & $49^{\circ} 28^{\prime} 24.388^{\prime \prime}$ & 763 \\
\hline 2 & $16^{\circ} 44^{\prime} 49.430^{\prime \prime}$ & $49^{\circ} 28^{\prime} 23.351^{\prime \prime}$ & 769 \\
\hline 3 & $16^{\circ} 44^{\prime} 49.780^{\prime \prime}$ & $49^{\circ} 28^{\prime} 23.362^{\prime \prime}$ & 770 \\
\hline 4 & $16^{\circ} 44^{\prime} 50.845^{\prime \prime}$ & $49^{\circ} 28^{\prime} 22.919^{\prime \prime}$ & 773 \\
\hline 5 & $16^{\circ} 44^{\prime} 49.427^{\prime \prime}$ & $49^{\circ} 28^{\prime} 19.430^{\prime \prime}$ & 780 \\
\hline 6 & $16^{\circ} 44^{\prime} 51.634^{\prime \prime}$ & $49^{\circ} 28^{\prime} 13.580^{\prime \prime}$ & 793 \\
\hline 7 & $16^{\circ} 44^{\prime} 52.595^{\prime \prime}$ & $49^{\circ} 28^{\prime} 11.626^{\prime \prime}$ & 790 \\
\hline 8 & $16^{\circ} 45^{\prime} 0.184^{\prime \prime}$ & $49^{\circ} 28^{\prime} 11.798^{\prime \prime}$ & 823 \\
\hline 9 & $16^{\circ} 45^{\prime} 0.248^{\prime \prime}$ & $49^{\circ} 28^{\prime} 11.586^{\prime \prime}$ & 824 \\
\hline 10 & $16^{\circ} 45^{\prime} 1.800^{\prime \prime}$ & $49^{\circ} 28^{\prime} 13.440^{\prime \prime}$ & 820 \\
\hline 11 & $16^{\circ} 44^{\prime} 58.700^{\prime \prime}$ & $49^{\circ} 28^{\prime} 23.898^{\prime \prime}$ & 789 \\
\hline 12 & $16^{\circ} 45^{\prime} 1.606^{\prime \prime}$ & $49^{\circ} 28^{\prime} 24.483^{\prime \prime}$ & 785 \\
\hline 13 & $16^{\circ} 45^{\prime} 1.480^{\prime \prime}$ & $49^{\circ} 28^{\prime} 25.018^{\prime \prime}$ & 793 \\
\hline 14 & $16^{\circ} 45^{\prime} 3.348^{\prime \prime}$ & $49^{\circ} 28^{\prime} 25.064^{\prime \prime}$ & 797 \\
\hline 16 & $16^{\circ} 45^{\prime} 4.799^{\prime \prime}$ & $49^{\circ} 28^{\prime} 22.775^{\prime \prime}$ & 799 \\
\hline
\end{tabular}




\begin{tabular}{|l|c|c|c|}
\hline 17 & $16^{\circ} 45^{\prime} 6.710^{\prime \prime}$ & $49^{\circ} 28^{\prime} 32.113^{\prime \prime}$ & 781 \\
\hline 18 & $16^{\circ} 45^{\prime} 5.620^{\prime \prime}$ & $49^{\circ} 28^{\prime} 32.192^{\prime \prime}$ & 782 \\
\hline 19 & $16^{\circ} 45^{\prime} 5.587^{\prime \prime}$ & $49^{\circ} 28^{\prime} 32.398^{\prime \prime}$ & 781 \\
\hline 20 & $16^{\circ} 45^{\prime} 16.211^{\prime \prime}$ & $49^{\circ} 28^{\prime} 30.166^{\prime \prime}$ & 778 \\
\hline 21 & $16^{\circ} 45^{\prime} 14.976^{\prime \prime}$ & $49^{\circ} 28^{\prime} 28.002^{\prime \prime}$ & 785 \\
\hline 22 & $16^{\circ} 45^{\prime} 13.964^{\prime \prime}$ & $49^{\circ} 28^{\prime} 27.822^{\prime \prime}$ & 787 \\
\hline 23 & $16^{\circ} 45^{\prime} 19.408^{\prime \prime}$ & $49^{\circ} 28^{\prime} 33.964^{\prime \prime}$ & 771 \\
\hline 24 & $16^{\circ} 45^{\prime} 1.645^{\prime \prime}$ & $49^{\circ} 28^{\prime} 19.034^{\prime \prime}$ & 806 \\
\hline 25 & $16^{\circ} 44^{\prime} 29.400^{\prime \prime}$ & $49^{\circ} 28^{\prime} 8.760^{\prime \prime}$ & 784 \\
\hline 26 & $16^{\circ} 44^{\prime} 30.120^{\prime \prime}$ & $49^{\circ} 28^{\prime} 10.200^{\prime \prime}$ & 783 \\
\hline 27 & $16^{\circ} 44^{\prime} 30.840^{\prime \prime}$ & $49^{\circ} 28^{\prime} 1.560^{\prime \prime}$ & 779 \\
\hline 28 & $16^{\circ} 44^{\prime} 27.240^{\prime \prime}$ & $49^{\circ} 27^{\prime} 57.960^{\prime \prime}$ & 790 \\
\hline 29 & $16^{\circ} 44^{\prime} 21.840^{\prime \prime}$ & $49^{\circ} 27^{\prime} 51.840^{\prime \prime}$ & 813 \\
\hline 30 & $16^{\circ} 44^{\prime} 19.509^{\prime \prime}$ & $49^{\circ} 27^{\prime} 50.008^{\prime \prime}$ & 820 \\
\hline
\end{tabular}

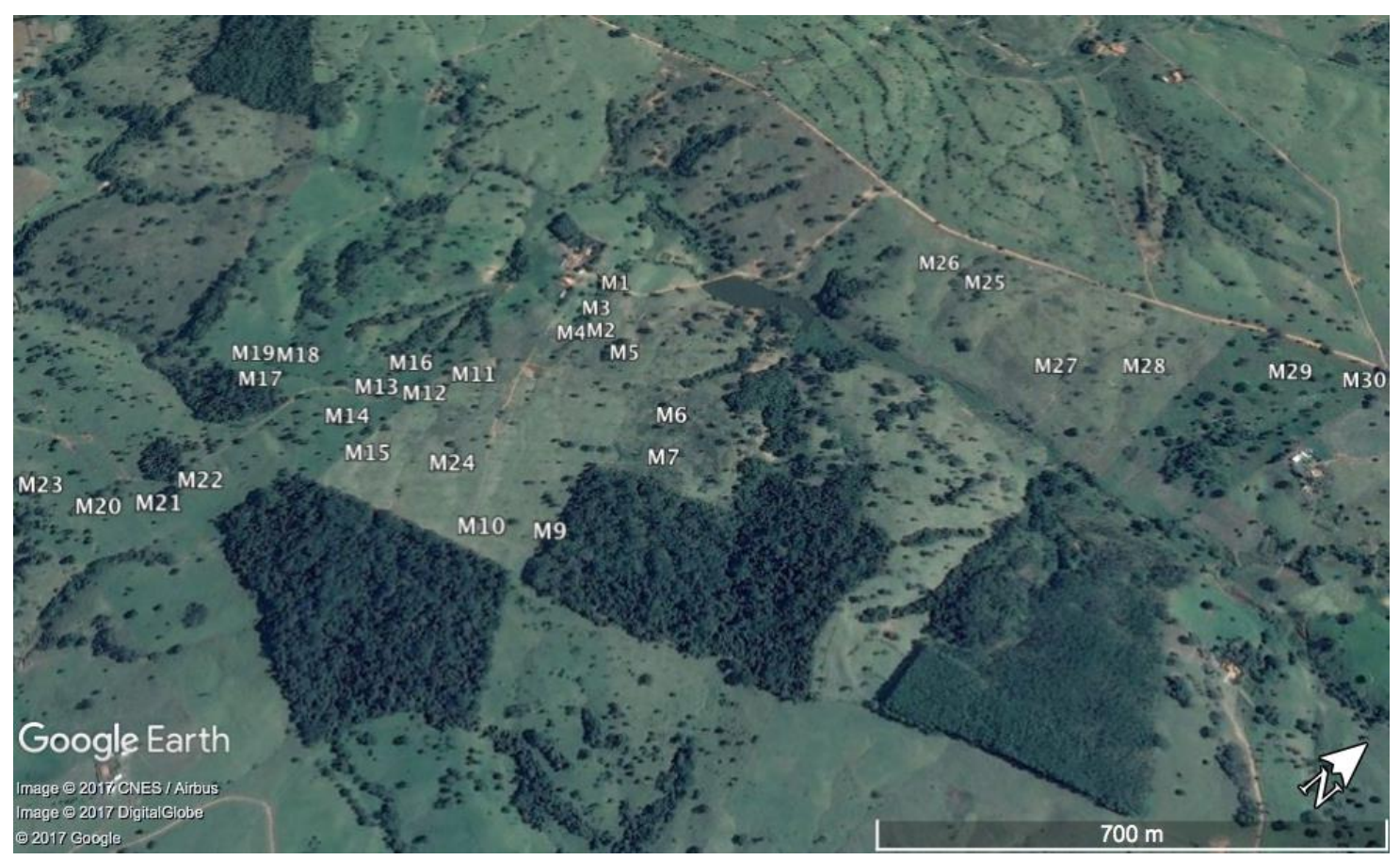

Figura 3: Distribuição e localização espacial das matrizes de Myracrodruon urundeuva coletadas do presente estudo. Fonte: Google Earth (2017).

\section{LOCAL DE EXECUÇÃO}

O teste de germinação, bem como os testes de determinação do teor de umidade, tanto pelo método do forno de micro-ondas como pelos métodos da estufa e do aparelho medidor de umidade foram realizados no Laboratório de Sementes e Viveiros Florestais do Departamento de Engenharia Florestal na Faculdade de Tecnologia da Universidade de Brasília. 
Parte do beneficiamento das sementes, a retirada da ala, foi realizada no local de coleta e parte no laboratório supracitado.

\subsection{PREPARAÇÕES DOS LOTES}

Após o beneficiamento as sementes foram contadas e separadas de acordo com a necessidade do experimento. Nos métodos para determinação do teor de umidade utilizou-se 135 propágulos para cada uma das quatro repetições de cada uma das 30 matrizes. Já no teste de germinação, foram empregados 40 diásporos para cada uma das repetições.

\subsection{DETERMINAÇÃO DO TEOR DE UMIDADE DOS LOTES}

\subsubsection{DETERMINAÇÃO DO TEOR DE UMIDADE PELO MÉTODO DA ESTUFA - MÉTODO 1}

Em um medidor de umidade da marca Marte ${ }^{\circledR}$, modelo ID200, com capacidade máxima de $210 \mathrm{~g}$ e mínima de $0,01 \mathrm{~g}$, realizou-se a pesagem das sementes das quatro repetições de cada matriz. Em seguida os propágulos de cada repetição foram colocados separadamente em recipientes metálicos, sendo então dispostos em uma estufa de circulação de ar por convecção natural da marca LUCADEMA ${ }^{\circledR}$, modelo $80 / 100$, por 24 horas a $105^{\circ} \mathrm{C} \pm$ $3^{\circ} \mathrm{C}$. Ao término do tempo estabelecido, os receptáculos com os indivíduos foram dispostos em um dessecador durante 30 minutos para resfriamento (Figura 3). Após esse processo as sementes foram novamente pesadas para obtenção do peso da matéria seca.

Realizou-se a determinação de umidade das sementes de acordo com a Regra de Análises de Sementes (BRASIL, 2009). O percentual de umidade das sementes foi obtido pela Equação 1:

$$
\% \text { de umidade }(U)=100 \times \frac{(P-p)}{P}
$$

Onde:

$\mathrm{P}=$ peso inicial, peso da semente úmida;

$\mathrm{p}=$ peso final, peso da semente seca; 


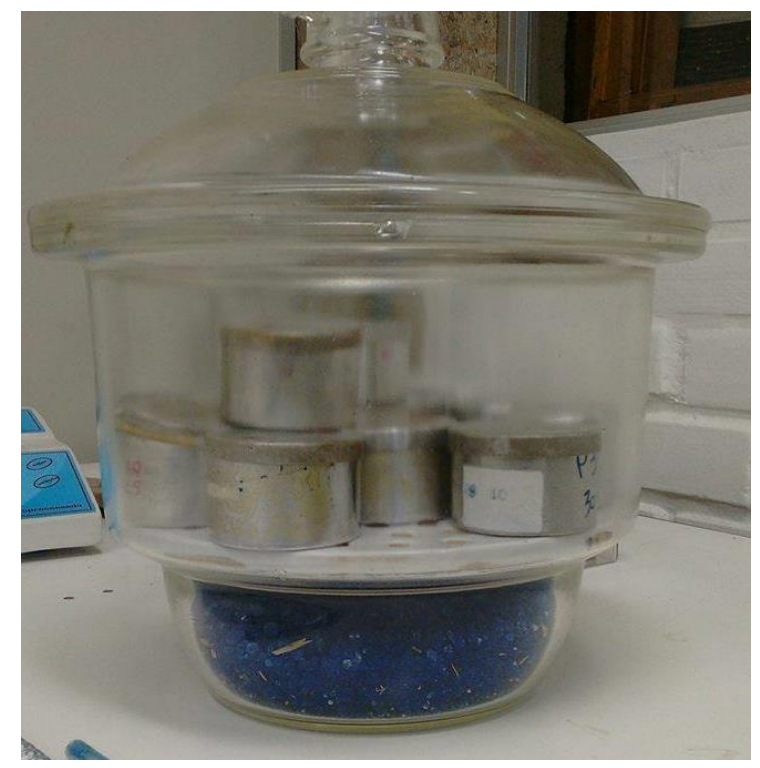

Figura 4: Recipientes metálicos no dessecador. Souza (2017).

\subsubsection{DETERMINAÇÃO DO TEOR DE UMIDADE PELO MÉTODO DO APARELHO DE MICRO-ONDAS - MÉTODO 2}

Para cada matriz de Myracrodruon urundeuva aplicou-se a metodologia "Amostra Única", descrita por Nery et al. (2004).

Introduziu-se em um aparelho de micro-ondas convencional da marca Philco ${ }^{\circledR}$ de 100 w de potência, um conjunto de 4 placas de petri (uma para cada repetição) com $60 \mathrm{~mm}$ de diâmetro. Cada placa continha 135 sementes previamente pesadas e, no centro, um Becker graduado com $125 \mathrm{~mL}$ de água destilada (Figura 4).

Os conjuntos de placas de cada matriz foram expostos por 3 minutos ao forno de micro-ondas com posterior resfriamento em dessecador durante 2 minutos, seguindo-se imediatamente para a pesagem das sementes após serem retiradas da vidraria. Após a pesagem o mesmo material retornou ao forno de micro-ondas por mais 5 minutos, e assim, consecutivamente, por 7, 9 e 11 minutos de exposição. O quadro 2 a seguir apresenta o procedimento. 
Quadro 2: Determinação de umidade das sementes de Myracrodruon urundeuva empregando-se a metodologia da “Amostra Única” (NERY et al., 2004).

\begin{tabular}{|l|c|c|c|c|c|c|c|c|c|}
\cline { 2 - 10 } \multicolumn{1}{c|}{} & \multicolumn{9}{c|}{ Tempo(min) } \\
\cline { 2 - 10 } \multicolumn{1}{c|}{} & 3 & 2 & 5 & 2 & 7 & 2 & 9 & 2 & 11 \\
\hline Micro-ondas & $\mathrm{X}$ & & $\mathrm{x}$ & & $\mathrm{x}$ & & $\mathrm{x}$ & & $\mathrm{x}$ \\
\hline $\begin{array}{l}\text { Pesagem/ } \\
\text { Resfriamento }\end{array}$ & & $\mathrm{x}$ & & $\mathrm{x}$ & & $\mathrm{x}$ & & $\mathrm{x}$ & \\
\hline
\end{tabular}

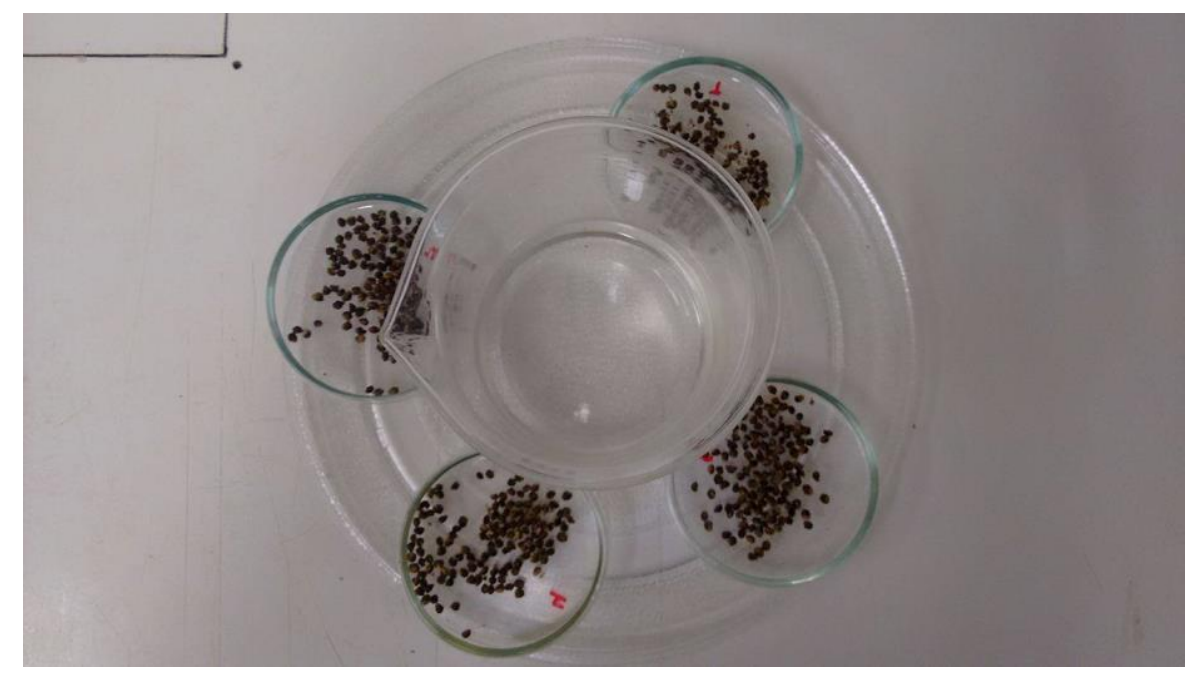

Figura 5: Disposição das placas de petri e Becker no prato do aparelho micro-ondas. Fonte: Souza (2017).

\subsubsection{DETERMINAÇÃO DO TEOR DE UMIDADE PELO MÉTODO DO APARELHO MEDIDOR DE UMIDADE - MÉTODO 3}

Em um medidor de umidade com fonte de calor infravermelho da marca Marte ${ }^{\circledR}$, modelo ID200, com capacidade máxima de $210 \mathrm{~g}$ e mínima de $0,01 \mathrm{~g}$, na programação automática, foram colocadas, uma de cada vez, as quatro repetições das trinta matrizes (Figura 5).

Na programação automática, utilizada no experimento, esse equipamento desidrata a amostra na temperatura de $105^{\circ} \mathrm{C}$ até não haver variância de $0,01 \%$ do peso inicial em um período de 30 segundos. 


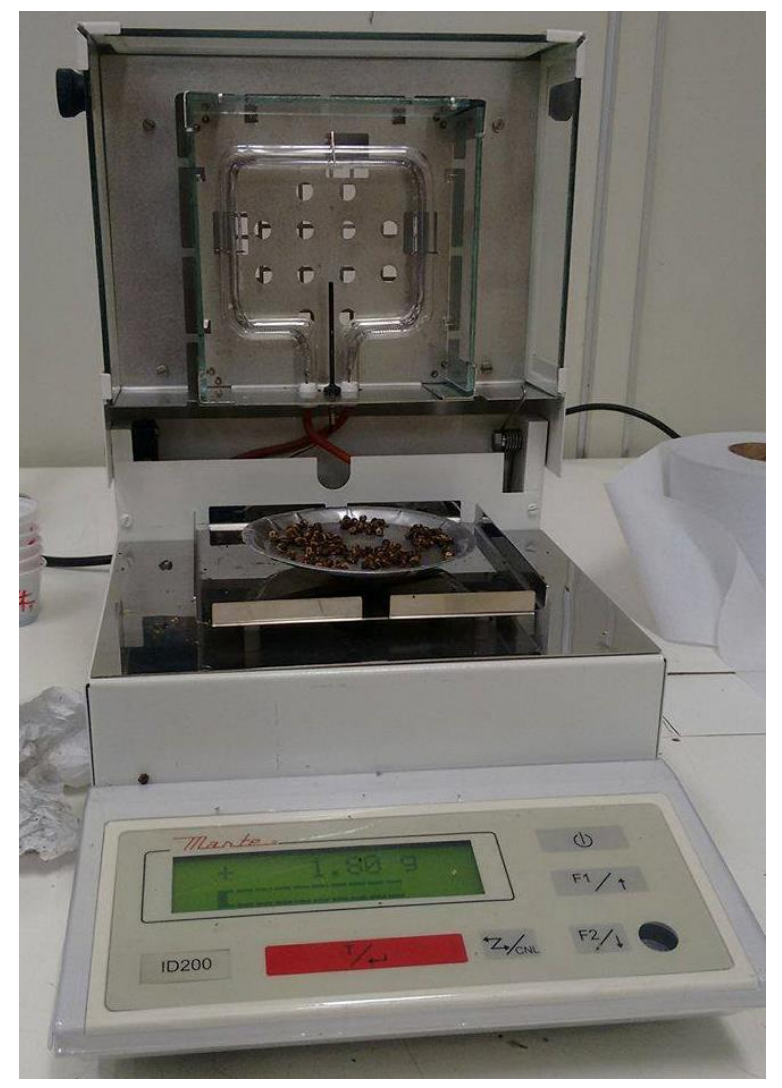

Figura 6: Medidor de umidade com uma repetição. Fonte: Souza (2017)

\subsection{ANÁLISE DE GERMINAÇÃO DAS SEMENTES}

Seguindo as regras de análise de sementes (BRASIL, 2009), os propágulos foram dispostos, de forma equidistante, sobre duas folhas de papel filtro e cobertas por uma terceira (Figura 6). O acondicionamento das folhas em sacos plásticos transparentes se realizou após seu umedecimento com água destilada, alcançando o ponto onde se formou uma película de água em torno das sementes evitando-se, contudo, o excesso do líquido.

Os sacos foram acomodados em uma câmara de germinação da marca LUCADEMA $^{\circledR}$ modelo Luca 161/02, com temperatura constante calibrada para $25^{\circ} \mathrm{C}$, e fotoperíodo ajustado para 12 horas.

As matrizes foram distribuídas em 4 repetições, sendo que cada uma reuniu 40 sementes. Realizaram-se seis verificações em um período de trinta dias: a primeira após dois de instalação do experimento, a segunda após quatro dias, a terceira após dez, a quarta após dezessete, a quinta após vinte e quatro e a última verificação no trigésimo dia.

Quando se fazia necessário, durante as verificações, os papeis filtro eram umedecidos. 
Considerou-se como germinado o propágulo que apresentou a emissão de radícula igual ou superior a 2,0 mm (Figura 7), respeitando a definição botânica de germinação (KERBAUY, 2008).

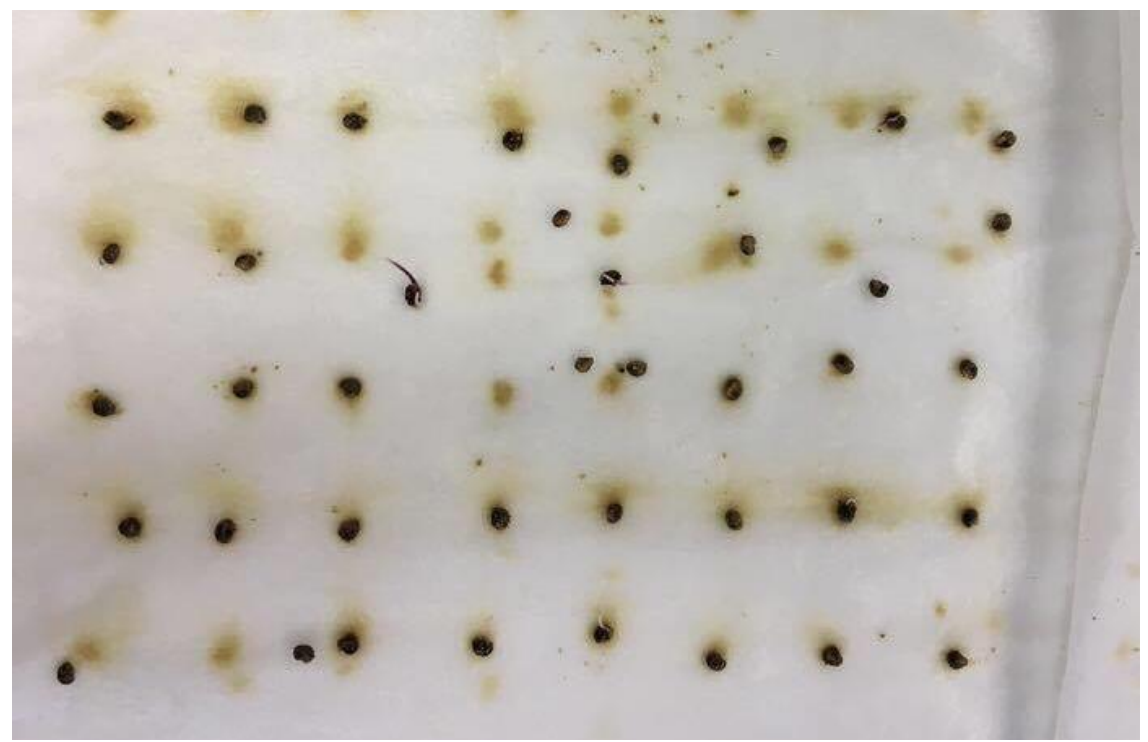

Figura 7: Disposição dos propágulos sobre folhas de papel filtro. Fonte: Souza (2017)

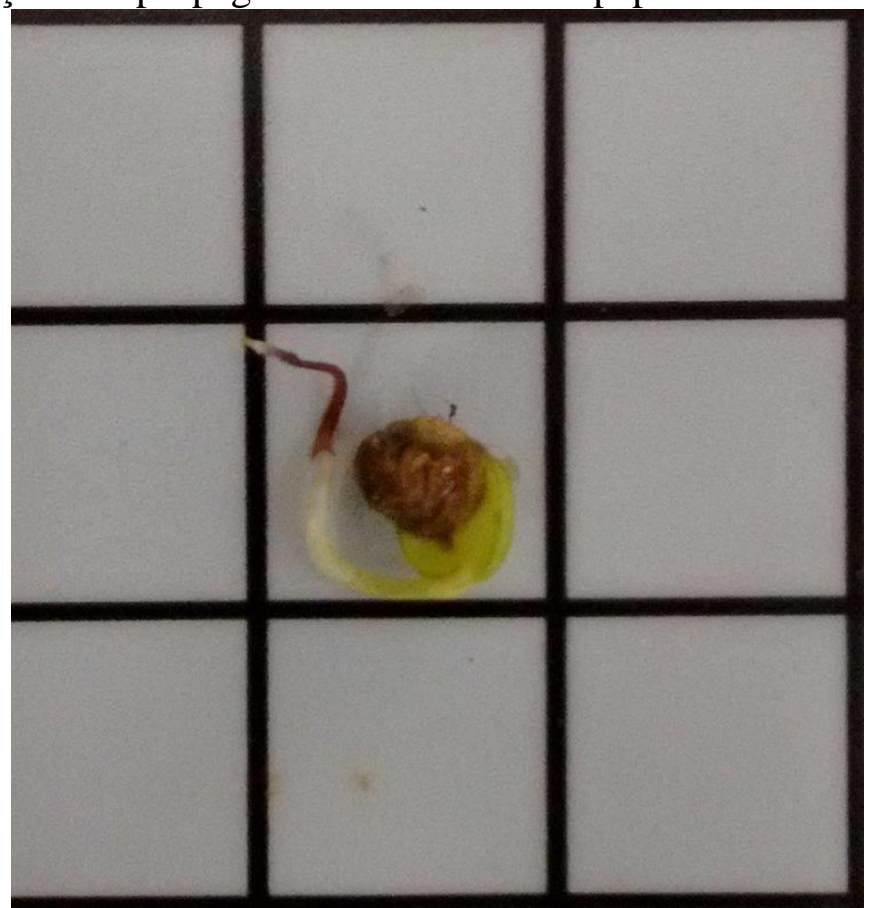

Figura 8: Propágulo com radícula igual ou superior a 2,0 $\mathrm{mm}$ sobre papel quadriculado 1 x $1 \mathrm{~cm}$. Fonte: Souza (2017). 


\section{ANÁLISE ESTATÍSTICA}

$\mathrm{O}$ experimento adotou o delineamento inteiramente casualizado (DIC) com três tratamentos, com quatro repetições de 135 sementes, para cada tratamento. Utilizou-se o teste de Tukey para comparação das médias dos tratamentos. Toda a parte estatística foi realizada pelo software GENES (CRUZ, 2013). 


\section{RESULTADO E DISCUSSÕES}

\subsection{PESO MÉDIO DAS SEMENTES}

O peso médio das sementes de aroeira foi de $0,015 \mathrm{~g}$, com desvio padrão $0,002 \mathrm{~g}$. A figura 8 mostra o peso médio calculado para as quatro repetições de cada matriz. O menor valor encontrado, 0,011, provém das matrizes 14, 21, 30, enquanto o maior, 0,019, foi observado nas matrizes 3 e 23 .

Esses resultados se assemelham aos encontrados por Virgens et al. (2012) e Bandeira et al. (2017) sendo 0,014 $\mathrm{g}$ para o primeiro e 0,017 $\mathrm{g}$ para o segundo.

A sanidade da planta mãe bem como a disponibilidade de nutrientes e água interfere diretamente na massa das sementes que, por sua vez, é determinante no posterior desenvolvimento das plântulas (MARCOS FILHO, 2005).

Mesmo Nunes et al. (2008) constatando que a espécie estudada é altamente influenciada pelas condições locais, não se pode inferir que o peso dos diásporos, de modo geral, possa ter sido influenciado pela disposição das matrizes no ambiente.

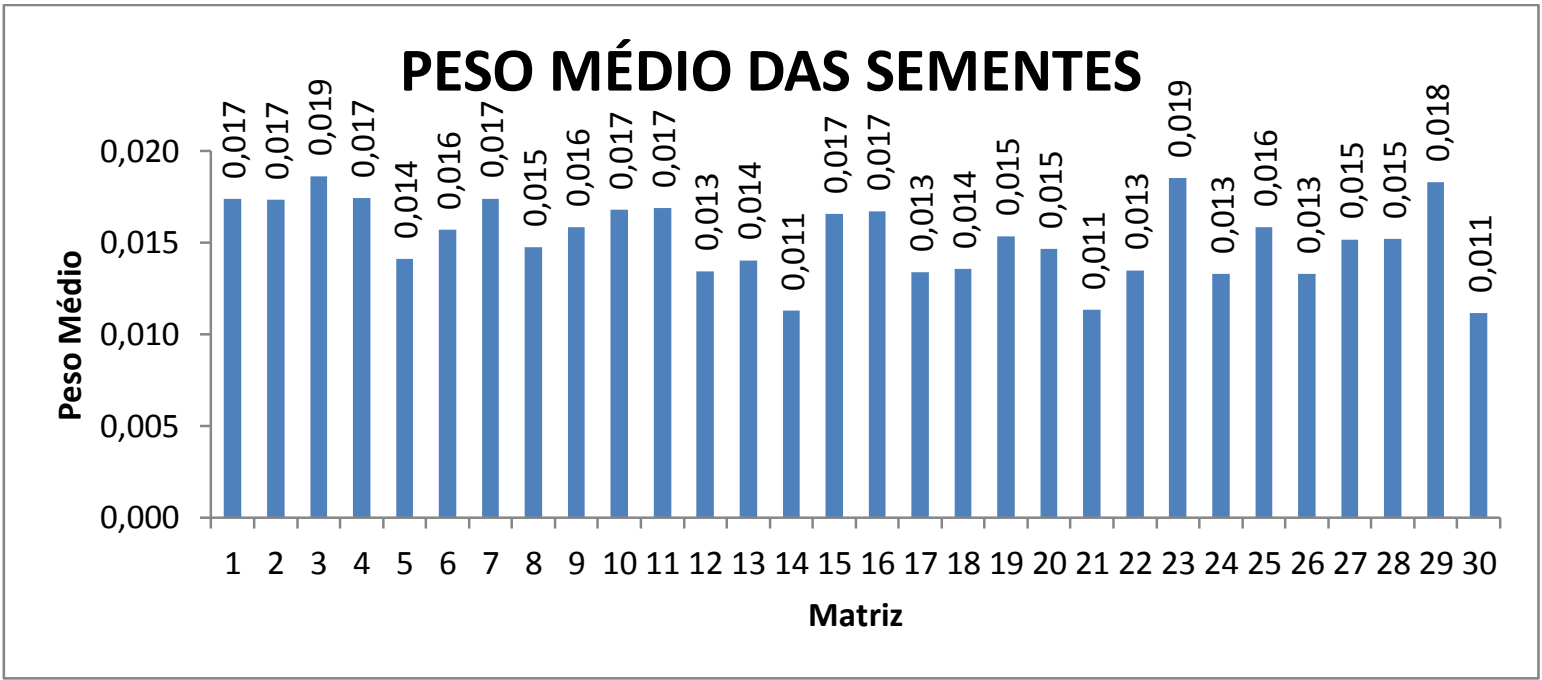

Figura 9: Peso médio das sementes para cada matriz de Myracrodruon urundeuva. 


\subsection{TEOR DE UMIDADE}

\subsubsection{ESTUFA}

Encontrou-se, para o método 1, umidade média de 13,57\% com desvio padrão de 3,87\%. Araujo et al. obteve para $M$. urundeuva no período de 24 horas em estufa, umidade igual a 8,62\% enquanto Caldeira \& Perez (2008) atingiram 9,7\%.

A espécie estudada, segundo Pelissari (2013), suporta o dessecamento, porém, BERJAK e seus colaboradores (2007) ressaltam que é difícil identificar com precisão, para qualquer espécie, o ponto exato de tolerância à dessecação.

O gênero Myracrodruon, cujas sementes são classificadas como ortodoxas, devem, de acordo com Marcos Filho (2005) ser desidratadas entre $8 \%$ e 10\% de sua massa para não sofrerem danos no potencial de germinação após o armazenamento.

Observa-se que para quase todas as matrizes o método de secagem em estufa se enquadra nesse limite, levando-se em conta o desvio padrão (Figura 10).

Os valores que se apresentam superiores ao estabelecido na literatura podem ser explicados pelas chuvas que acometeram a região onde se encontram as matrizes nos dias anteriores a colheita.

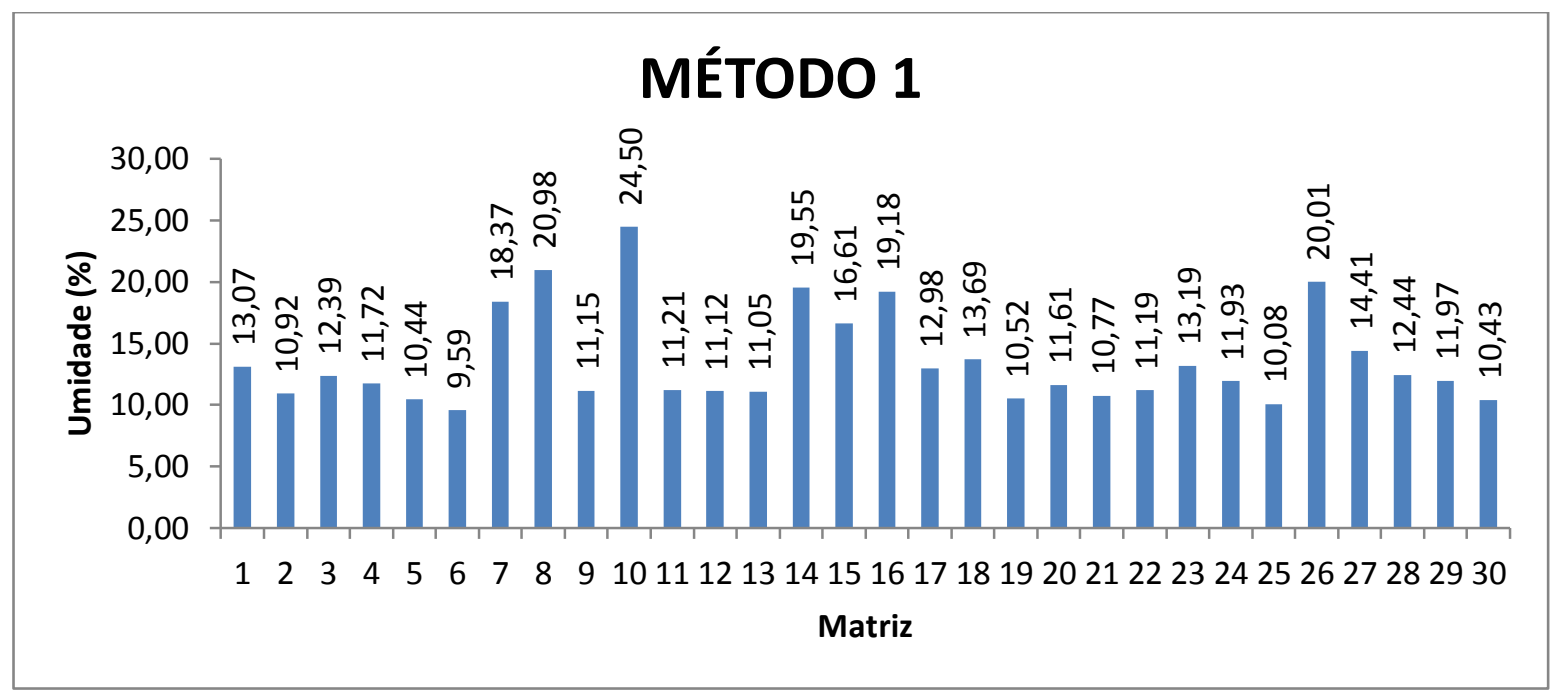

Figura 10: Média das sementes das matrizes de Myracrodruon urundeuva secas em estufa a $105^{\circ} \mathrm{C}$ por 24 horas. 


\subsubsection{APARELHO MEDIDOR DE UMIDADE}

O tempo médio necessário para as amostras secagem das amostras foi de 4 minutos 29 segundos e 52 centésimos com desvio padrão de 56 segundos e 47 centésimos.

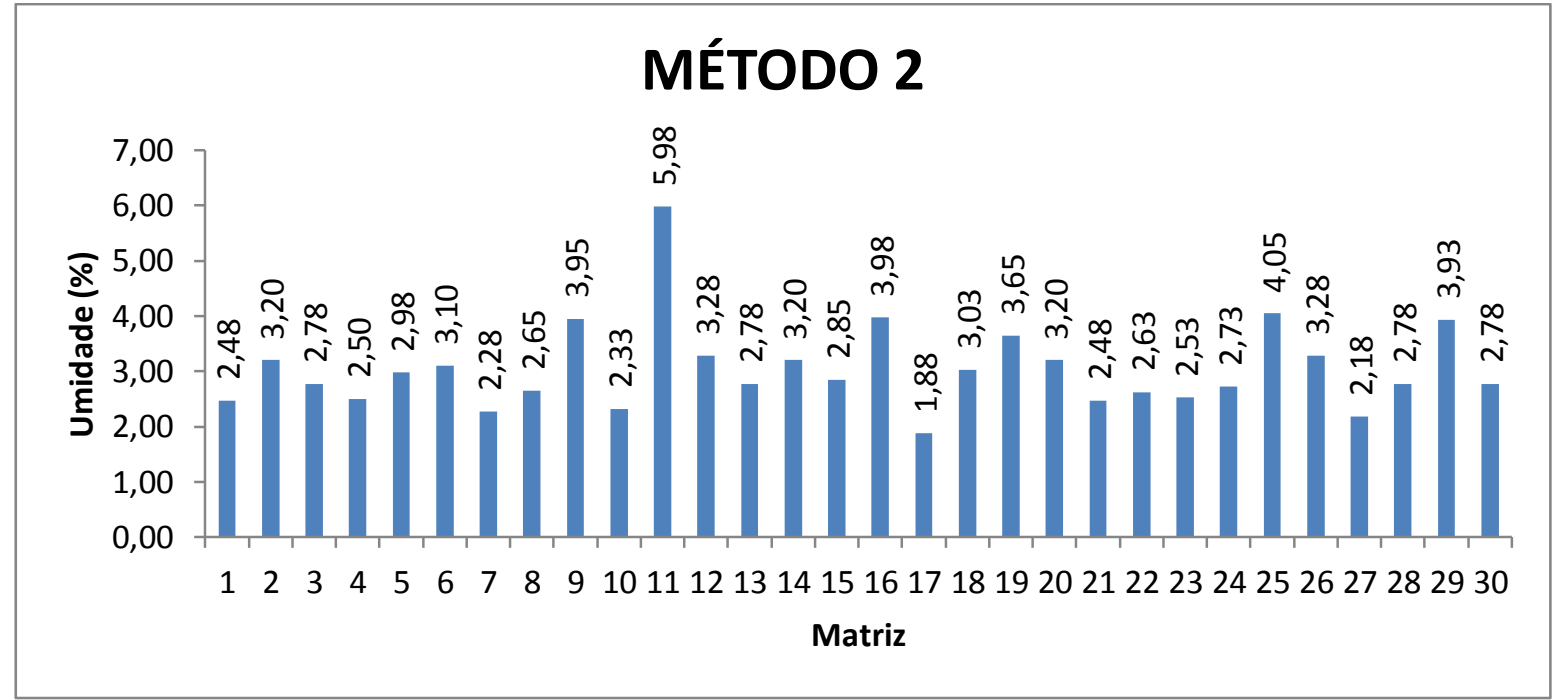

Figura 11: Média das sementes das matrizes de Myracrodruon urundeuva secas no medidor de umidade modelo ID200 na programação automática.

\subsubsection{FORNO MICRO-ONDAS}

O método 3 apresentou média de 11,09\% com desvio padrão de 2,53\%. Soares et al. (2003) ao realizar a secagem de trigo (T. aestivum L) em micro-ondas no tempo de 3 minutos encontrou $12,93 \%$ de umidade nos grãos.

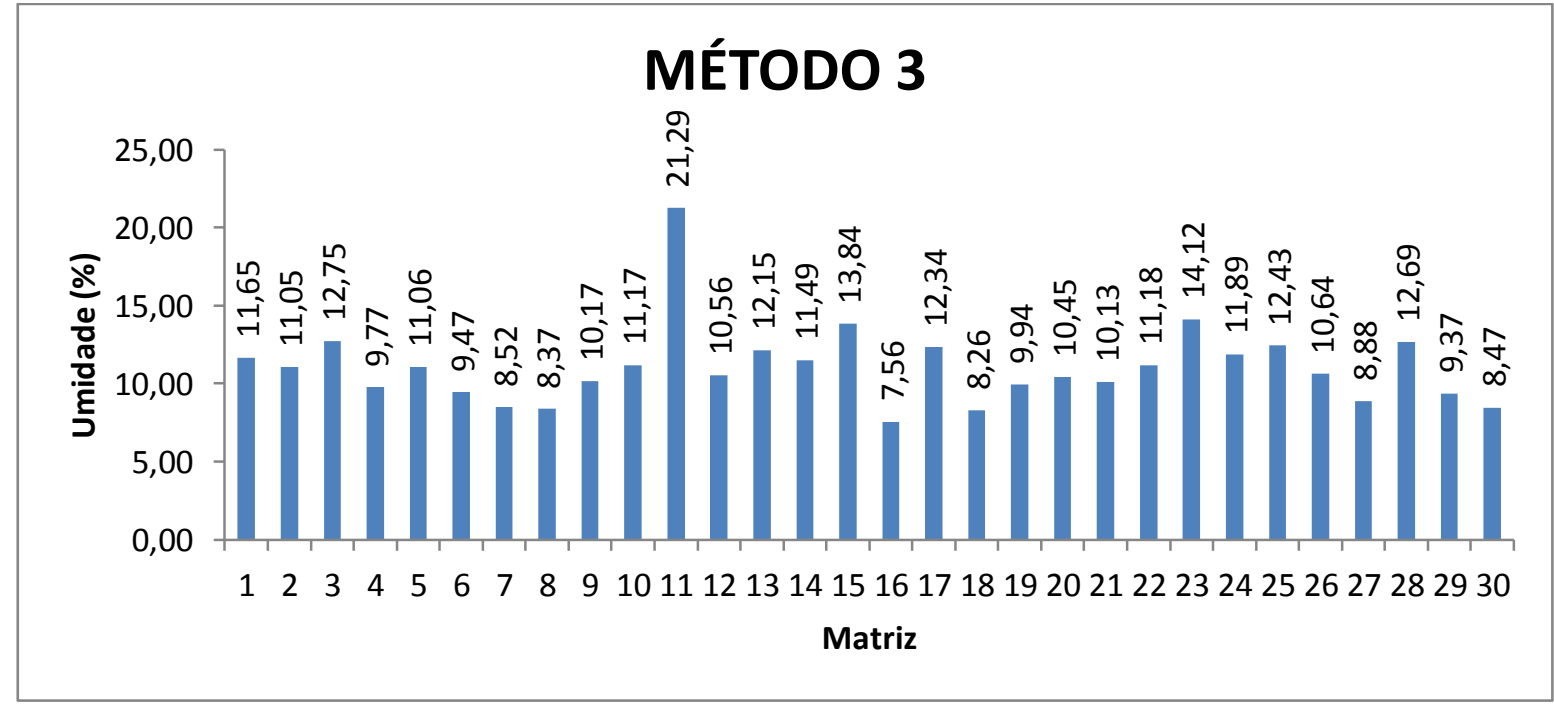

Figura 12: Média das sementes das matrizes de Myracrodruon urundeuva secas no forno micro-ondas. 
Levando-se em conta o valor estabelecido por Marcos Filho (2005) como ideal para dessecação dos propágulos, pode-se notar que a soma da umidade retirada nos tempos de 3 minutos, 5 minutos e 7 minutos encontra-se nesse intervalo (Figura 13).

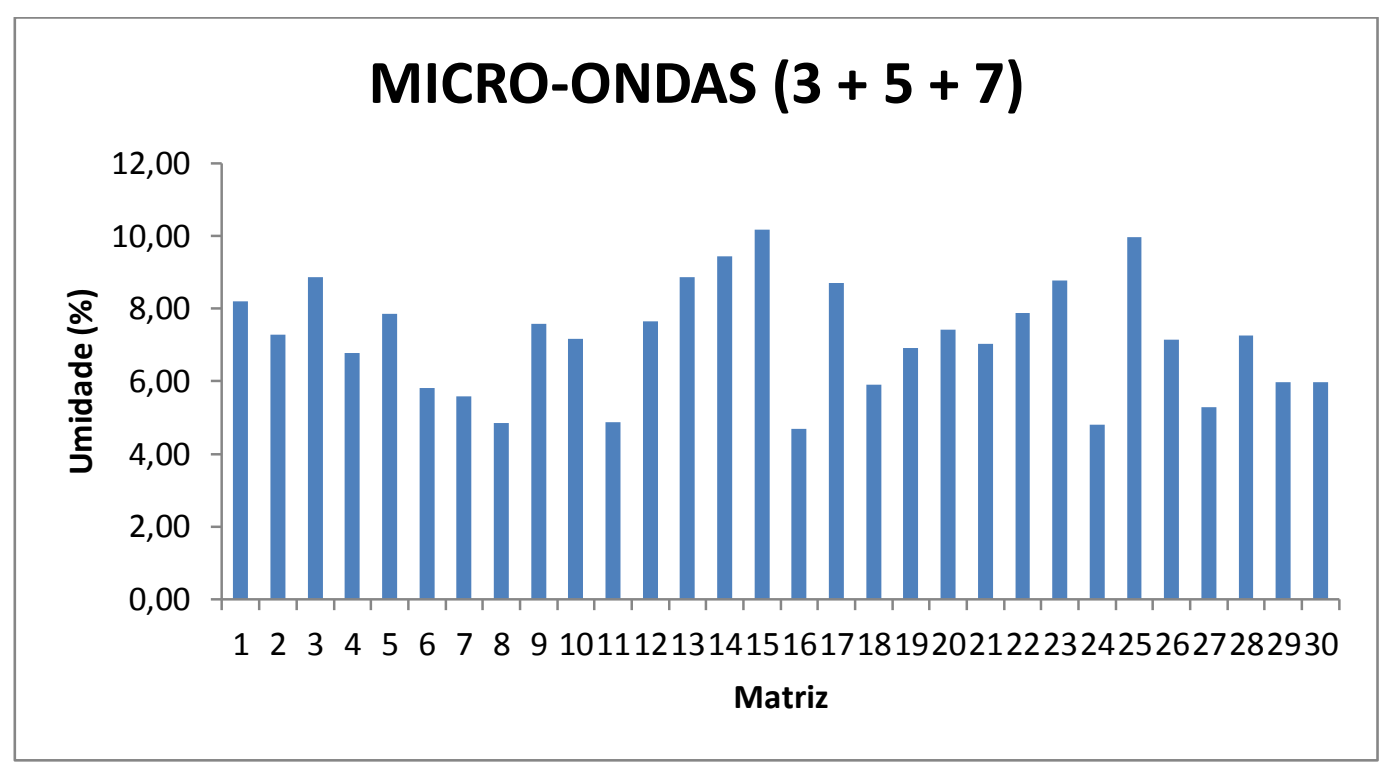

Figura 13: Soma do teor de umidade médio nos tempos 3, 5 e 7 do método 3.

Avaliando-se as taxas de umidade retiradas no somatório dos tempos 3 e 5, taxas essas levemente inferiores ao limite mínimo estabelecido, pode-se inferir que o tempo ideal para secagem, em forno micro-ondas, de sementes de $M$. urundeuva, encontra-se entre 8 minutos e 15 minutos (Figura 14).

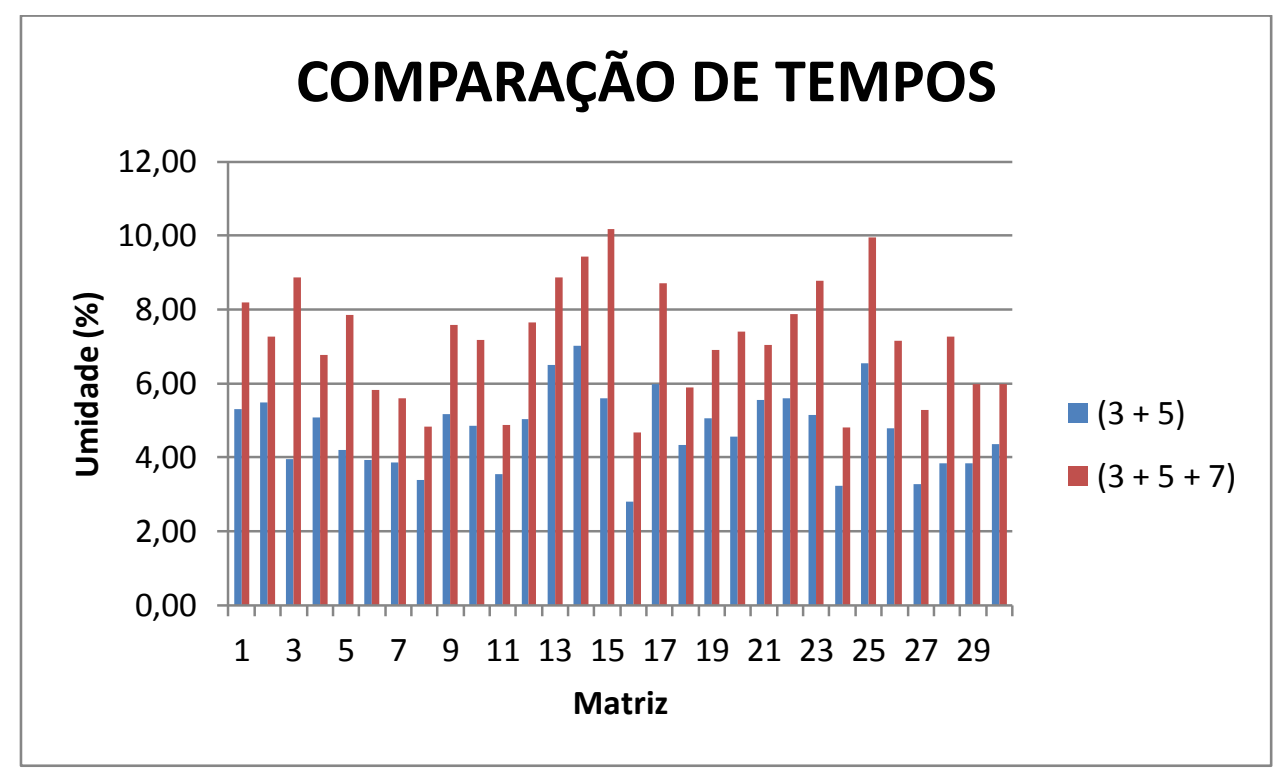

Figura 14: Comparação da soma do teor médio de umidade nos tempos 3, 5 e 7, e nos tempos 3 e 5 do método 3. 
Deve ser levada em consideração que os resultados obtidos no método 3 são provenientes da exposição intermitente da fonte de calor sobre os diásporos. A soma dos tempos não proporcionará o mesmo resultado que a secagem de forma contínua.

A exposição contínua ao dessecamento resultante do forno micro-ondas provavelmente trará resultados superiores de retirada de umidade em menor tempo, hipótese também levantada por Duarte (2015).

$\mathrm{Na}$ execução do experimento as amostras foram retiradas do forno e pesadas ao final de cada tempo estabelecido, isso expos as placas de petri ao ambiente externo repetidas vezes, o que levou ao resfriamento das mesmas e provável absorção de umidade durante as pesagens. Essa descontinuidade no experimento aumenta o tempo necessário para as sementes alcançarem o mesmo teor de umidade quando se realiza a secagem ininterrupta.

A utilização do Becker com $125 \mathrm{~mL}$ de água destilada para distribuir de forma homogênea os elétrons no interior do forno (CARVALHO et al., 1997) deve ser revista. Observou-se que nos maiores períodos de exposição a água sofre pequenas explosões, inutilizando assim, por umidificá-lo, o material do interior do aparelho. A utilização de cubos de gelo adicionados a água contida no Becker pode ser uma solução.

\subsubsection{COMPARAÇÃO DOS MÉTODOS}

Os altos teores de umidade (Figura 15), de forma geral, encontrados nos três métodos podem ser explicado, em parte, pela incidência de chuvas próximo ao período da colheita dos diásporos. De acordo com Carvalho (2005) isso ocorre porque os diásporos mais úmidos apresentam maior quantidade de água livre, que é mais facilmente removida do material.

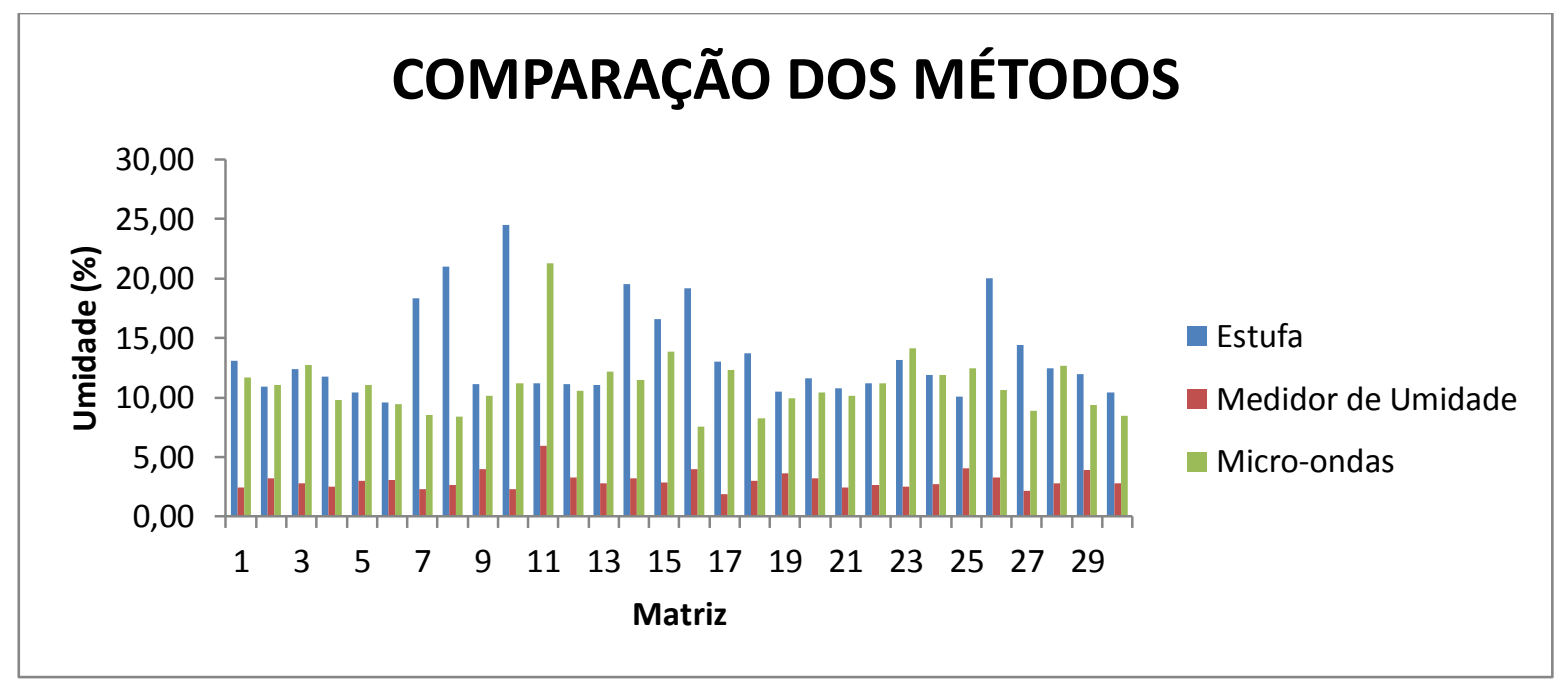

Figura 15:Comparação da retirada de umidade dos métodos 1, 2 e 3. 
A capacidade da estufa em acomodar de uma única vez um grande número de repetições de várias matrizes, pode ser entendida como uma vantagem em relação aos demais métodos testados.

A velocidade de execução e obtenção dos resultados é uma característica marcante para os três métodos, mas os obtidos pelo medidor de umidade ocorreram em um tempo médio bem inferior aos demais métodos.

A maior vantagem do aparelho medidor de umidade é a disposição dos resultados obtidos em tempo real através de uma tela lcd na qual o operador pode tomar suas decisões de acordo com o andamento do experimento, mas a sua capacidade limitada de deposição de diásporos reduz a sua funcionalidade. Esse aparelho mostra-se indicado para a determinação de pequenas amostras com posterior extrapolação dos dados para a população.

A utilização do forno de micro-ondas mostra-se como uma alternativa para os pequenos produtores por apresentar baixo custo relativo, sendo necessário apenas mais estudos para consolidar a técnica. Ao estudar o teor de umidade de grãos de milho e soja com micro-ondas, Pedrosa et al. (2014) concluiu que a secagem nesse aparelho é possível para essas sementes.

Os tratamentos diferiram estatisticamente entre si (Tabela 1), isso leva a conclusão que o método a ser empregado deve levar em consideração a finalidade da secagem.

Tabela 1: Médias do teor de umidade avaliadas nos tratamentos de secagem em estufa (Estufa), secagem em aparelho micro-ondas (Micro) e secagem em aparelho medidor de umidade (Medidor) aplicados em Myracrodruon urundeuva.

\begin{tabular}{cccccccc}
\hline & Trat. & Médias* & Trat. & Médias* & Trat. & Médias* & CV \% \\
\hline $\begin{array}{c}\text { Teor de } \\
\text { umidade }\end{array}$ & Estufa & 13,565 a & Micro & $\begin{array}{c}11,058 \\
\text { b }\end{array}$ & Medidor & $3,04 \mathrm{c}$ & 39,50 \\
\hline
\end{tabular}

Trat: Tratamento; CV: Coeficiente de variação; *: Médias com letras diferentes diferem pelo teste de Tukey em nível de 5\% de probabilidade.

\subsubsection{GERMINAÇÃO}

O resultado médio da germinação das sementes de Myracrodruon urundeuva obtido, 39,17 \%, condiz com o disponível na literatura (PACHECO, 2006; DORNELES et al., 2005).

A baixa porcentagem de germinação das matrizes 3, 7 e 30 pode ser explicada, em parte, pelo ataque fúngico ocorrido durante o experimento. De acordo com Ferraz \& Calvi 
(2010) o potencial germinativo das sementes, avaliado pelo teste de germinação, pode ser afetado pela presença de microrganismos.

As sementes de aroeira são extremamente suscetíveis ao ataque de fungos, como verificaram Faiad et al. (2000). Essa constatação é corroborada por Silva et al., (2015) que ao realizar germinação de sementes de aroeira a $45^{\circ} \mathrm{C}$, encontraram, após 8 dias, $98 \%$ de suas sementes colonizadas por fungos e uma taxa de germinação de $29 \%$.

Como medida para reduzir a incidência de fungos e outros patógenos, Pacheco (2006) esterilizou as sementes de M. urundeuva com solução de hipoclorito de sódio a 5\% durante 5 minutos com posterior lavagem em água destilada. Outra medida para minimizar a ação de fungos pode ser encontrada em Pina-Rodrigues et al. (2004) que observaram bons resultados quando da utilização de vermiculita e areia como substratos nos seus testes de germinação.

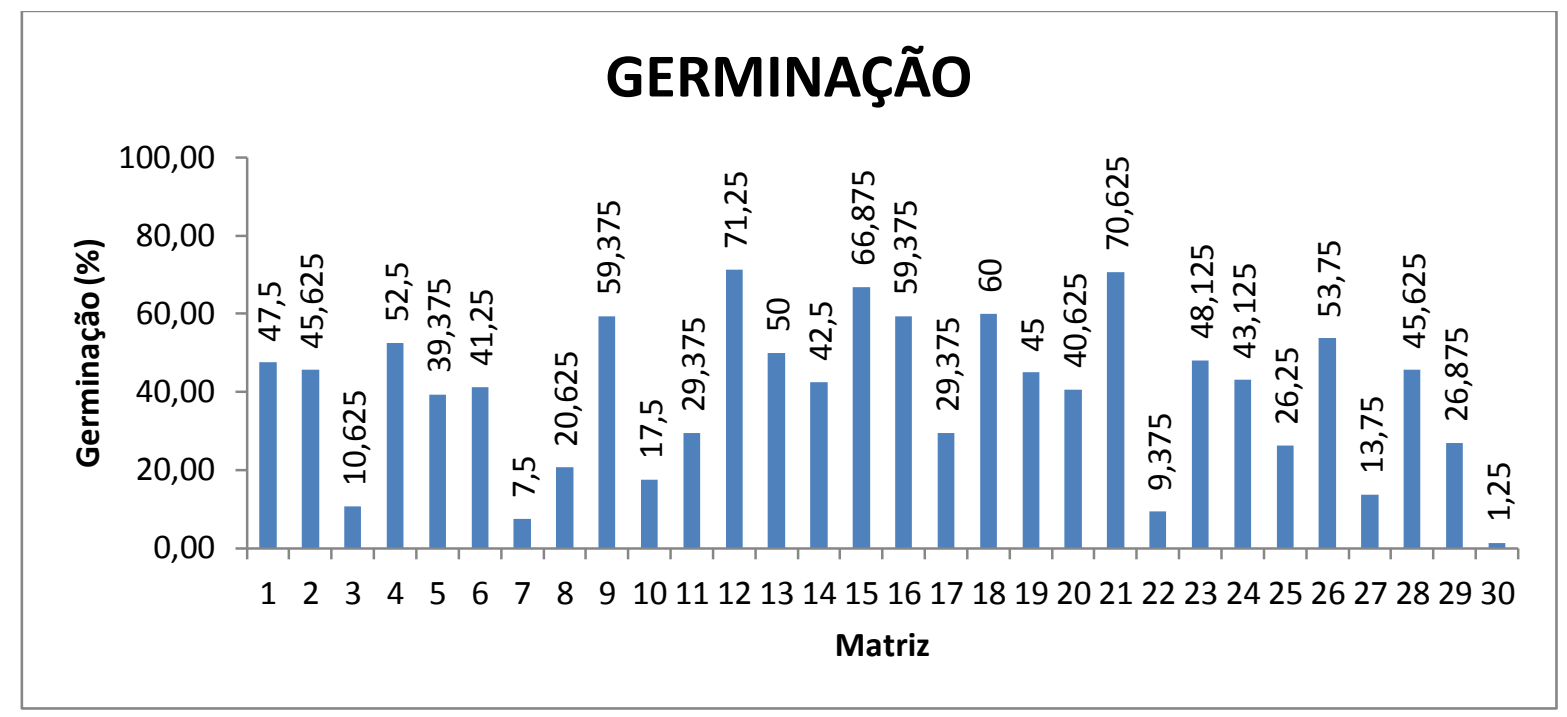

Figura 16: Germinação média das sementes em percentagem para cada matriz.

A espécie Myracrodruon urundeuva possui como uma de suas características a rápida germinação dos seus propágulos (DORNELES et al., 2005). No corrente estudo observou-se a germinação de 98,24\% dos diásporos nos primeiros quatro dias após a instalação do experimento, com os outros 1,65\% ocorrendo até o décimo dia (Figura 10). Essa rápida germinação indica que a espécie não possui dormência, não sendo necessário assim, escarificação tegumentar ou outra técnica de quebra de dormência. 


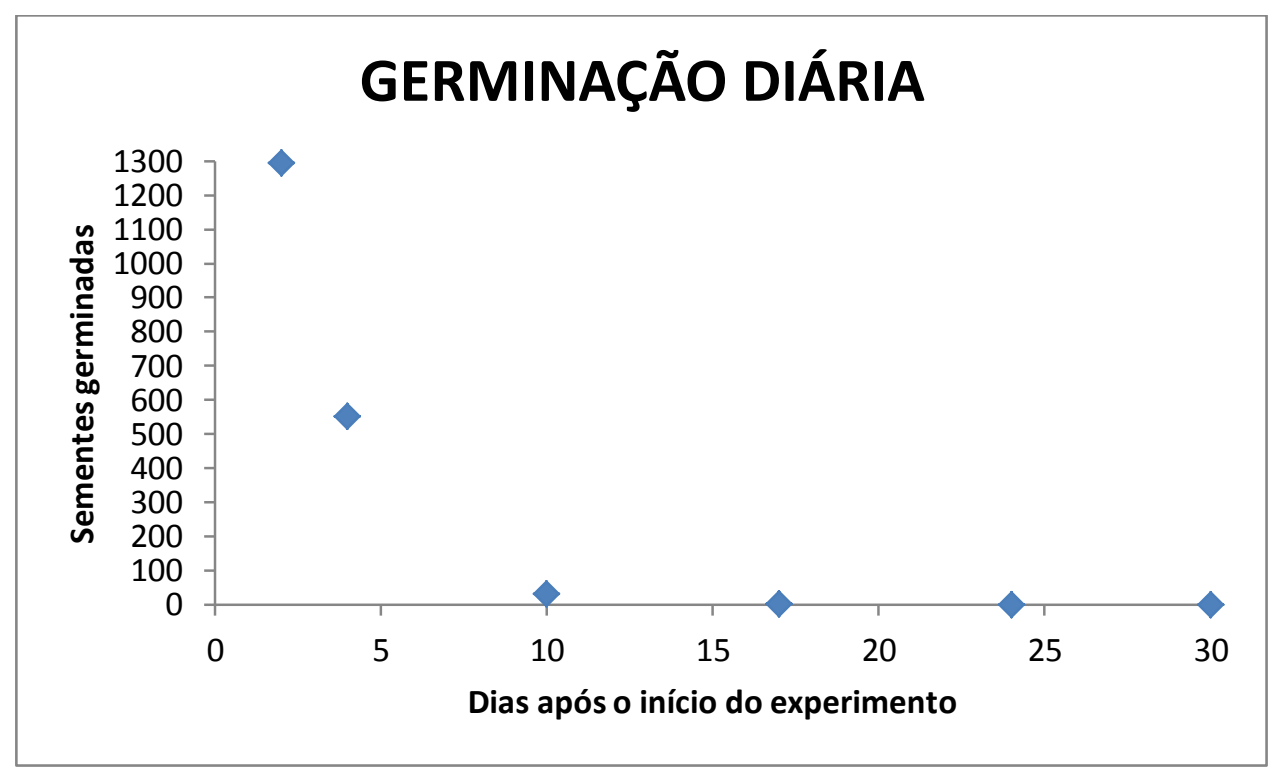

Figura 17: Germinação diária após o estabelecimento do experimento

A taxa similar de porcentagem de germinação e peso dos diásporos das matrizes 1, 2, e 4 pode ser entendida como reflexo da sua proximidade no campo, compartilhando assim, condições edafoclimáticas muito parecidas.

Deve ser ressaltado que as sementes da matriz 3 sofreram um severo ataque de fungos o que provavelmente foi o motivo da diferença tão acentuada entre sua germinação e os valores apresentados pelas matrizes 1,2 e 4 .

Não se pode inferir que o ambiente afetou diretamente na similaridade entre os resultados encontrados nas matrizes com valores superiores. Essas árvores encontram-se em diferentes condições ambientais, compartilhando somente o regime hidrológico.

\section{CONCLUSÃO}

Os resultados obtidos neste trabalho suportam as conclusões de que:

- $\quad$ A espécie estudada apresenta germinação concentrada nos primeiros dias após o umedecimento dos propágulos.

- $\quad$ O método de secagem utilizando o medidor de umidade foi o que menos desidratou os propágulos.

- As sementes da espécie estudada apresenta grande suscetibilidade ao ataque de patógenos. 
- A taxa de germinação da espécie estudada não é empecilho para seu emprego na produção de mudas.

- $\quad$ Os três métodos de secagem apresentaram resultados com diferenças estatisticamente relevantes.

- $\quad$ O método de secagem utilizando forno micro ondas apresenta potencial para aplicação prática sendo necessário a formulação e testes de protocolos adequados. 


\section{REFERÊNCIAS BIBLIOGRÁFICAS}

ALVES, P. M.; QUEIROZ, L G; PEREIRA, J. V.; PEREIRA, M. S. V. Atividade antimicrobiana, antiaderente e antifúngica in vitro de plantas medicinais brasileiras sobre microrganismos do biofilme dental e cepas do gênero Candida. Revista da Sociedade Brasileira de Medicina Tropical, v. 42, p. 1-3, 2009.

ARAUJO, M. N.; DANTAS, B. F.; PELACANI, C. R. Teor de água sobre a germinação de sementes de aroeira-do-sertão. MAGISTRA CRUZ DAS ALMAS-BA, v. 25, p. 414-415, 2013.

BACHELET, C.; VIALOU, A.V.; CECCANTINI, G.; VIALOU, D. Um tição de aroeira em contexto arqueológico: contribuição antracológica para a compreensão da relação entre o homem e o ambiente. Revista Museu Arqueologia e Etnologia, São Paulo, n. 21, p. 115-127, 2011.

BERJAK, P.; FARRANT, J.M.; PAMMENTER, N.W. Seed desiccation-tolerance mechanisms. In: Jenks, M.A; Wood, A.J. (org). Plant desiccation tolerance. Ames, IA: Blackwell Publishing. 2007

BANDEIRA, A. S. NUNES, R. T. C.; EVERARDES P. J.; e OTONIEL, M. M. Avaliação do potencial fisiológico das unidades de propagação de aroeira (Myracrodruon urundeuva), com e sem exocarpo e mesocarpo, em diferentes substratos. Revista de Ciências Agrárias, Lisboa, v. 40, n. 1, p. 53-60, 2017.

BARBEDO, C.J.; MARCOS-FILHO, J. Tolerância à dessecação em sementes. Acta Botânica Brasílica, São Paulo, v. 12, n.2, p. 145-164, 1998.

BARBOZA, A.C.R.N. ; CRUZ, M.B.G. ; MYRIAN, C.F. ; LORENZETTI, E.S.. Aquecimento em forno de micro-ondas/desenvolvimento de alguns conceitos fundamentais. Química Nova, v.24, n.6, p.901-904, 2001. 
BRANDÃO,M. Área Mineira do Polígono das Secas / Cobertura Vegetal. Informe Agropecu ário, v.17, n.181, p.5-9, 1994.

BRASIL. Ministério da Agricultura e da Reforma Agrária. Regras para análise de sementes. Brasília: Mapa/ACS. 399p., 2009.

BORGES, J. C.; RAMOS, A. S. ; SANTANA, L. M. B. ; DAMASCENO, B. P. G. L. Myracrodruon urundeuva allemão: atividadebiológica e potencial terapêutico. In: Congres so internacional da diversidade do semiárido, 2016, Campina Grande. Anais I CONIDIS, 2016.

BOTELHO, M. A.; RAO, V. S.; CARVALHO, C. B. M.; BEZERRA-FILHO, J. G.; FONSECA, S. G. C.; VALE, M. L.; MONTENEGRO, D.; CUNHA, F.; RIBEIRO, R. A.; BRITO, G. A. Lippia sidoides and Myracrodruon urundeuva gel prevents alveolar bone resorption in experimental periodontitis in rats. Journal of Ethnopharmacology, v.113, p. 471-478, 2007.

CALDEIRA, S. F.; PEREZ, S. C. J. G. A. Qualidade de diásporos de Myracrodruon urundeuva Fr. All. armazenados sob diferentes condições. Revista Brasileira de Sementes, v. 30, p. 185-194, 2008.

CARLINI, E. A.; DUARTE-ALMEIDA, J. M.; RODRIGUES, E.; TABACH, R. Antiulcer effect of the pepper trees Schinus terebinthifolius Raddi (aroeira-da-praia) and Myracrodruon urundeuva Allemao, Anacardiaceae (aroeira-do-sertao). Revista Brasileira De Farmacognosia, v. 20, p. 140-6, 2010.

CARVALHO, L. R. de; DAVIDE, A. C.; MALAVASI, M. de M. Determinação do grau de umidade de sementes de espécies florestais utilizando forno de microondas. 1997. Graduação (Monografia) - Universidade Federal de Lavras, Lavras, 1997.

CARVALHO, N.M.; NAKAGAWA, J. Secagem de sementes. In: Sementes: ciência, tecnologia e produção. 4.ed. Jaboticabal: FUNEP, 2000a. p.380- 415. 
CARVALHO, N.M. A secagem de sementes. 2.ed. Jaboticabal: Funep, 2005. 184p.

CARVALHO, P. E. R. Espécies Arbóreas Brasileiras. 1. ed. Brasília: Embrapa Informação Tecnológica, v. 1, p. 1039, 2003a.

CARVAlHO, P. E. R. Circular técnica: Aroeira - verdadeira. Embrapa Florestas. Colombo - PR, p. 1 - 16, $2003 b$.

CAVALCANTI, R. Fitodontologia. 1. ed. Rio Branco-AC: Clube dos Autores, v. 1, p. 268, 2013.

CHAGAS, M. B. das. Prospecção química e microbiológica do óleo essencial de espécimens de M. Urundeuva (aroeira-do-sertão) quimiotipos 3-careno e ocimeno. 2015. 61 f. TCC - Curso de Química, Centro de Ciências Exatas e da Terra, Universidade Federal do Rio Grande do Norte, Natal, 2015.

CHRIST, D; CORRÊA, P.; ALVARENGA, E. M. Efeito da temperatura e da umidade relativa do ar de secagem sobre a qualidade fisiológica de sementes de canola (Brassica napus L. var. oleifera Metzg.). Revista Brasileira de Sementes, v. 19, n. 2, p. 150-154, 1997.

CLIMATE-DATA.ORG. Clima: Abadia de Goiás. Disponível em: < https://pt.climatedata.org/location/312876/> Acesso em: 15 de agosto de 2017.

CUNHA, A. O.; ANDRADE, L. A.; BRUNO, R. L. A, SIlvA, J. A. L.; SOUZA, V. C. Efeitos de substratos e das dimensões dos recipientes na qualidade das mudas de Tabebuia impetiginosa (Mart. Ex D.C.) Standl. Revista Árvore, 29(4): 507-516, 2005.

CRUZ, C. D. GENES - a software package for analysis in experimental statistics and quantitative genetics. Acta Scientiarum. Agronomy, v. 35, p. 271-276. 2013. 
DORNELES, M. C.; RANAL, M. A.; SANTANA, D.G. Germinação de diásporos recémcolhidos de Myracrodruon urundeuva Allemão (Anacardiaceae) ocorrente no cerrado do Brasil Central. Revista Brasileira de Botânica, v.28, n.2, p.399-408, 2005.

DUARTE, G. V. Avaliação de sementes de Copaifera langsdorffii Desf submetidas a dois métodos de análise do teor de umidade. 2015. 34 f., il. Monografia (Bacharelado em Engenharia Florestal)—Universidade de Brasília, Brasília, 2015.

FAIAD, M.G.R.; SALOMÃO, A.N.; SILVA, J.A.; PADILHA, L.S.; MUNDIM, R.C. Recursos genéticos: ocorrência de fungos em sementes de espécies nativas. Brasília: Embrapa Recursos Genéticos e Biotecnologia, 2000.

FERRAZ, I. D. K.; CALVI, D. P. Teste de Germinação. In: LIMA JUNIOR, M. J. V. (Ed.). Manual de Procedimentos para Análise de Sementes Florestais. Manaus: UFAM, 2010. p. 55110.

GARCIA, J.P; MARTINS, R.C.C. ; FERREIRA, J.C.B. ; SILVA, I.M.A..Viabilidade e biometria de sementes de Mimosa heringeri BARNEBY. Dissertação de Mestrado em Ciências Florestais, Universidade de Brasília, p. 5, 2013.

GARCIA, L. G. C. ; VENDRUSCOLO, F. ; SILVA, F. A. . Determinação do teor de água em farinhas por micro-ondas. Revista Brasileira de Produtos Agroindustriais , v. 16, p. 17-25, 2014.

GOES, A.C.A.M.; RODRIGUES, L.V.; MENEZES, D.B.; GRANGEIRO, M.P.F. \& CAVALCANTE, A.R.M.S. Análise histológica da cicatrização da anastomose colônica, em ratos, sob ação de enema de aroeira-do-sertão (Myracrodruon urundeuva Fr. All.) a 10\%. Acta Cirúrgica Brasileira, v. 20, p. 144-151, 2005.

GOOGLE. Google Earth Pro. 2017. Abadia de Goiás. Acesso em: 01 de Dezembro de 2017. 
GUEDES, R. S. A, E. U.; BRUNO, R. L. A.; GONÇALVES, E. P.; COSTA, E. G.; MEDEIROS, M. S. Armazenamento de sementes de Myracrodruon urundeuva Fr. All. em diferentes embalagens e ambientes. Rev. bras. plantas med., Botucatu , v. 14, n. 1, p. 68$75, \quad 2012$

HARTMANN, HUDSON THOMAS.; KESTER, DALE E. Propagacion de plantas: Principios y practicas. México, DF: Contineltal, p. 814, 1981.

IBÁ - Indústria Brasileira de Árvores. Relatório IBA 2016. São Paulo. 2016.

KERBAUY, G. B. Fisiologia Vetetal - Segunda edição expandida, revisada e atualizada. 2a. ed. Rio de Janeiro: Editora Guanabara Koogan Ltda., 2008.

KOHOMA, S.; MALUF, A. M.; BILIA, D. A. C.; BARBEDO, C. J. Secagem e armazenamento de sementes de Eugenia brasiliensis Lam. (Grumixameira). Rev. bras. Sementes. 2006, vol.28, n.1, pp.72-78.

LORENZI, H. Árvores brasileiras: manual de identificação e cultivo de plantas arbóreas nativas do Brasil. São Paulo: Plantarum, v.1, p. 368, 1992.

LORZA, R. F.; SOUZA, F. M.; NAKASHIMA, R. Pomares de sementes de espécies nativas: situação atual e propostas. In: Higa, A. R.; Silva, L. D. (Coord.). Pomar de sementes de espécies florestais nativas. Curitiba: FUPEF do Paraná, cap. 2, p. 41-64, 2006.

LUCENA, R. F. P.; FARIAS, D.C.; CARVALHO, T.K.N. ; LUCENA, C.M. ; VASCONCELOS NETO, C. F. A. ; ALBUQUERQUE, U.P. Uso e conhecimento da aroeira (Myracrodruon urundeuva) por comunidades tradicionais no Semiárido brasileiro. Sitientibus. Série Ciências Biológicas, v. 11, p. 255-264, 2011.

MARCOS FILHO, J. Fisiologia de sementes de plantas cultivadas. Piracicaba: FEALQ, p.495, 2005. 
MATOS, F. J. A. Plantas medicinais: guia de seleção e emprego de plantas usadas em fitoterapia no Nordeste do Brasil. 3. ed. Fortaleza: UFC, v. 1, p. 394, 2007.

MEDEIROS, A. C. S.; EIRA, M. T. S. Comportamento Fisiológico, Secagem e Armazenamento de Sementes Florestais Nativas. Colombo-PR: Embrapa Florestas, Circular técnica, № 127, 2006.

MELO, P.R.B. Qualidade fisiológica e armazenamento de sementes de ipêverde(Cybistax antisyphilitica (Mart.) Mart.). Tese (doutorado) - Universidade Estadual Paulista, Faculdade de Ciências Agrárias e Veterinárias, 2009.

MENDONÇA, R. C.; FELFILI, J. M.; WALTER, B. M. T.; SILVA JÚNIOR, M. C.; REZENDE, A. V.; FILGUEIRAS, T. S.; NOGUEIRA, P. E.; FAGG, C. W. Flora vascular do bioma cerrado, p. $\underline{423-442}$. In: S.M. Sano \& S.P. Almeida. Cerrado, Ambiente e flora. Planaltina, EMBRAPA CPAC. 2008.

MENEGHELlO, G. Qualidade: umidade e temperatura. Seed News, XVIII, p. 28-33, 2014.

MMA. (2008). Instrução Normativa nº 06, de 23 de Setembro de 2008.

MONTEIRO, M. J.; ELCIDA, A. L.; AMORIM, E. L. C.; ALBUQUERQUE, U. P. Valuation of the Aroeira (Myracrodruon urundeuva Allemão) perspectives on conservation. Acta Botanica Brasilica, v.26, n.1, p.125-132, 2012.

NERY, M. C.; CARVALHO, M. L. M.; OLIVEIRA, L. M. Determinação do grau de umidade de sementes de ipê-do-cerrado Tabebuia ochracea ((Cham.) Standl.) pelos métodos de estufa e forno de microondas. Ciênc. agrotec., Lavras , v. 28, n. 6, p. 1299-1305, 2004.

NUNES, Y. R. F.; FAGUNDES, M.; ALMEIDA, H. D. S.; VELOSO, M. D. M. Aspectos ecológicos da aroeira (Myracrodruon urundeuva Allemão-Anacardiaceae): fenologia e germinação de sementes. Revista Árvore., vol.32, n.2, 2008. 
NUNES, A. P.; SANTOS JUNIOR, A. Itens alimentates consumidos por psitacídeos no Pantanal e planaltos do entorno, Mato Grosso do Sul. Atualidades Ornitológicas, v. 162, p. 42-50, 2011.

OLMOS, F.; MARTUSCELLI, P.; SILVA E SILVA, R. Distribution and dry-season ecology of Pfrimer's Conure Pyrrhura pfrimeri, with a reappraisal of Brazilian Pyrrhura "leucotis". Orn. Neotrop. 8: p.121-132, 1997.

OMS. Antimicrobial Resistance. Global Report on Surveillance 2014. Organização Mundial de Saúde: Genebra, 2014.

PACHECO, M. V.; MATOS, V. P.; CARACIOLO, R L F.; FELICIANO, A. L. P.; PINTO K. M. S. Efeito de temperaturas e substratos na germinação de sementes de Myracrodruon urundeuva Fr. All. (Anacardiaceae). Revista Árvore, v. 30, n. 3, p. 359-367, 2006.

PEDROSA, C. R. G.; MELO, L. F.; FAGIOLI M. Viabilidade do uso de aparelho de microondas na determinação do teor de água em sementes de milho e soja. Revista Agropecuária Técnica, v. 35, n.1, p48-53, 2014.

PELISSARI, F. Estudos da Tolerância à dessecação em sementes de espécies florestais nativas oriundas do norte de Mato Grosso. 2013. 75 p. Dissertação (Mestrado em Ciências Ambientais) - Universidade Federal de Mato Grosso, Sinop, 2013.

PINÃ-RODRIGUES, F. C. M.; FIGLIOLIA, M. B.; PEIXOTO, M. C. Testes de qualidade. In: FERREIRA, A. G.; BORGHETTI, F. (Orgs.) Germinação: do básico ao aplicado. Porto Alegre: Artmed, p. 283-297, 2004.

POPINIGIS, F. Fisiologia de sementes. 2.ed. Brasília, s/Ed., p. 289, 1985. 
SANTOS, J. S. Cariri e Tarairiús? Culturas Tapuias nos Sertões da Paraíba. Porto Alegre. 2009. 732 p. Tese. (Doutorado em História/Arqueologia). Pontifícia Universidade Católica do Rio Grande do Sul - PUC/RS: Porto Alegre, 2009.

SARMENTO, M. G. ; NOBRE, A. C. ; AMARO, H. T. R.. Determinação do teor de água em sementes de milho, feijão e pinhão-manso por métodos alternativos. Energia Na Agricultura, 30(3):249-256, 2015.

SCALON, S. de P. Q.; SCALON FILHO, H.; MASETTO, T. E. Aspectos da germinação e desenvolvimento inicial de plântulas de aroeira. CERNE. 2012, vol.18, n.4, pp.533-539.

SILVA, R. M.; ANGELOTTI, F.; BARROS, J. R. A.; OLIVEIRA, N. P.; REGO, M. T. C.; OLIVEIRA, F. O. E. C.; DANTAS, B. F. Germinação de Sementes de Aroeira (Myracrodruon urundeuva Allemão) e Incidência de Fungos em Elevadas Temperaturas. In: IV Simpósio de Mudanças Climáticas e Desertificação no Semiárido Brasileiro, 2015, Petrolina. Anais do IV Simpósio de Mudanças Climáticas e Desertificação no Semiárido Brasileiro. Petrolina: Embrapa Semiárido, 2015.

SILVA, E. C. C.. Secagem e armazenamento de sementes de Eugenia dysenterica DC. Dissertação (mestrado em ciências agrárias) - Universidade Federal de São João del - Rei, 2015 .

SOARES, G. J. D.; MONKS, L. F.; COSTA, C. S. . Efeito das Microondas na Secagem de Trigo (Triticum aestivum, L.) e na Qualidade Reológica da Farinha. Alimentos e Nutrição (UNESP), v. 14, p. 219-224, 2003.

SOUZA, F. H. Produção de sementes de Arachis pintoi cv. BRS Mandobi no Acre. Embrapa Acre. Sistemas de Produção, 4. Versão Eletrônica, 2011.

SOUZA, L. A. Teste de condutividade elétrica para avaliação da qualidade de sementes de mamona. Dissertação (Mestrado em Agronomia) - Universidade de Lavras, Lavras, Minas Gerais, p. 53, 2007. 
STURION; J. A.; ANTUNES, B. M. A. Produção de mudas de espécies florestais. In: GALVÃO, A.P.M. Reflorestamento de propriedades rurais para fins de produtivos e ambientais, Colombo, p.125-150, 2000.

VASCONCELOS, M. F.; D'ANGELO NETO, S.; HOFFMANN， D.; GOMES, H. B . Natural history notes on parrots feeding on fruits of Myracrodruon urundeuva (Anacardiaceae) in three South American dry forest regions. Cotinga (Sandy), Sandy, v. 26, p. 15-19, 2006.

VIEIRA, R. D. Condutividade elétrica e teor de água inicial das sementes de soja. Pesquisa agropecuária brasileira, Brasília, v. 37, n. 9, p. 1333-1338, 2002.

VIRGENS， I. O.; CASTRO, R. D.; FERNANDEZ， L. G.; PELACANI， C. R. COMPORTAMENTO FISIOLÓGICO DE SEMENTES DE Myracrodruon urundeuva Fr. All. (Anacardiaceae) SUBMETIDAS A FATORES ABIÓTICOS. Ciência Florestal, v. 22, p. 681-692, 2012 